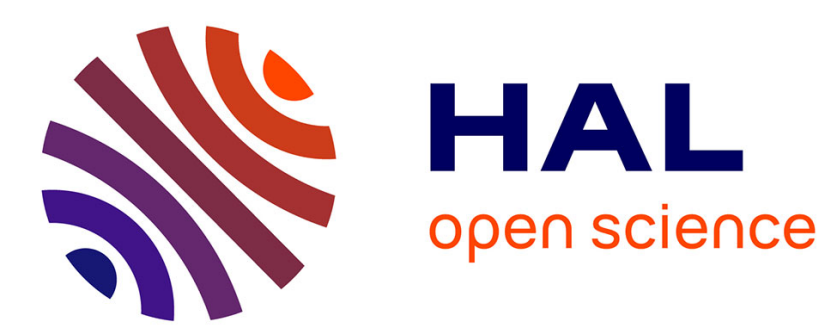

\title{
Shear wave crustal velocity model of the Western Bohemian Massif from Love wave phase velocity dispersion
}

\author{
Petr Kolínský, Jiří Málek, Johana Brokešová
}

\section{To cite this version:}

Petr Kolínský, Jiří Málek, Johana Brokešová. Shear wave crustal velocity model of the Western Bohemian Massif from Love wave phase velocity dispersion. Journal of Seismology, 2010, 15 (1), pp.81-104. 10.1007/s10950-010-9209-4 . hal-00623786

\section{HAL Id: hal-00623786 \\ https://hal.science/hal-00623786}

Submitted on 15 Sep 2011

HAL is a multi-disciplinary open access archive for the deposit and dissemination of scientific research documents, whether they are published or not. The documents may come from teaching and research institutions in France or abroad, or from public or private research centers.
L'archive ouverte pluridisciplinaire HAL, est destinée au dépôt et à la diffusion de documents scientifiques de niveau recherche, publiés ou non, émanant des établissements d'enseignement et de recherche français ou étrangers, des laboratoires publics ou privés. 


\title{
Shear wave crustal velocity model of the Western Bohemian Massif from Love wave phase velocity dispersion
}

1

2 3 4

5

6

\author{
Petr Kolínský ${ }^{1}$, Jiř́i Málek ${ }^{1}$ and Johana Brokešová ${ }^{2}$ \\ 1) Department of Seismology \\ Institute of Rock Structure and Mechanics \\ Academy of Sciences of the Czech Republic, v.v.i. \\ V Holešovičkách 41, 18209 Praha 8, Czech Republic \\ 2) Department of Geophysics \\ Faculty of Mathematics and Physics \\ Charles University in Prague \\ V Holešovičkách 2, 18000 Praha 8, Czech Republic
}

P. Kolínský (corresponding author): kolinsky@irsm.cas.cz

Revised manuscript submitted for publication in the Journal of Seismology

\section{Abstract}

We propose a new quantitative determination of shear wave velocities for distinct geological units in the Bohemian Massif, Czech Republic (Central Europe). The phase velocities of fundamental Love wave modes are measured along two long profiles ( $200 \mathrm{~km}$ ) crossing three major geological units and one rift-like structure of the studied region. We have developed a modified version of the classical multiple filtering technique for the frequency-time analysis and we apply it to two-station phase velocity estimation. Tests of both the analysis and inversion are provided. Seismograms of three Aegean Sea earthquakes are analyzed. One of the two profiles is further divided into four shorter sub-profiles. The long profiles yield smooth dispersion curves; while the curves of the sub-profiles have complicated shapes. Dispersion curve undulations are interpreted as perioddependent apparent velocity anomalies caused both by different backazimuths of surface wave propagation and by surface wave mode coupling. An appropriate backazimuth of propagation is found for each period, and the dispersion curves are corrected for this true propagation direction. Both the curves for the long and short profiles are inverted for a 1D shear wave velocity model of the crust. Subsurface shear wave velocities are found to be around $2.9 \mathrm{~km} / \mathrm{s}$ for all four studied sub-profiles. Two of the profiles crossing the older Moldanubian and Teplá-Barrandian units are characterized by higher velocities of $3.8 \mathrm{~km} / \mathrm{s}$ in the upper crust while for the Saxothuringian unit we find the velocity slightly lower, around $3.6 \mathrm{~km} / \mathrm{s}$ at the same depths. We obtain an indication of a shear wave low velocity zone above Moho in the Moldanubian and Teplá-Barrandian units. The area of the Eger Rift (Teplá-Barrandian - Saxothuringian unit contact) is significantly different from all other three units. Low upper crust velocities suggest sedimentary and volcanic filling of the rift as well as fluid activity causing the earthquake swarms. Higher velocities in the lower crust together with weak or even missing Moho implies the upper mantle updoming.

Key words: Love waves, phase velocity dispersion, frequency-time analysis, structure inversion, Bohemian Massif

\section{Introduction}


Our present study is a new contribution to the effort of determining the shear wave model of the crust in the Western Bohemian Massif. This region is characterized by three major geological units. Details concerning geophysical surveys and geological settings of these units can be found in Vrána et al. (1997) for the Moldanubian unit, in Cháb et al. (1997) for the 1 Teplá-Barrandian unit and in Mlčoch et al. (1997) for the Saxothuringian unit.

The Moldanubian unit is the oldest of the units consolidated during the Proterozoic to Paleozoic age. Its crystalline composition experienced high-pressure and high-temperature metamorphosis. Lithological composition proves crust-mantle interaction. Smaller bodies intruded the unit during the Variscan orogeny. The Teplá-Barrandian unit is slightly younger. Its Neoproterozoic parts are slightly metamorphosed while its older Paleozoic parts are not metamorphosed at all. It has a more heterogeneous density than the Moldanubian unit and displays a positive gravimetric anomaly. The boundary between the Teplá-Barrandian and Moldanubian units is of tectonic origin. The Saxothuringian unit is again formed by Proterozoic and Cambrian metamorphosed rocks with Variscan intrusions. It is characterized by a negative gravimetric anomaly. The boundary between the Saxothuringian and Teplá-Barrandian units is formed by the Eger rift, which is a linear tectonic structure filled with Tertiary sediments complemented by Neogenic volcanism.

The history of seismic survey of the Earth crust and uppermost mantle of the Bohemian Massif covers more than forty years. Refraction and reflection experiments as well as surface wave studies along several profiles crossing the Bohemian Massif have been performed.

In the 1960s, an international deep seismic sounding profile was shot across the southwestern Bohemian Massif. Data were interpreted by Beránek (1971) and Beránek et al. (1973). Beránek (1971) gave an indication of lower velocities in the upper and middle crust for the Teplá-Barrandian and Moldanubian units - he interpreted it as evidence of their sedimentary composition and pointed out the fact that we can find low velocities down to the depths of $20 \mathrm{~km}$ although these units are so old.

Beránek and Zounková (1977) complemented the results from the deep seismic sounding profile by measurements of Pwave velocities from quarry blasts round the whole Czech Republic. They constructed a map of the Moho discontinuity, which was the deepest beneath the Moldanubian unit $-39 \mathrm{~km}$. The Moho then rises in all directions towards the edges of the Bohemian Massif.

In the 1990s, reflection profile 9HR was shot in the southwestern part of the Bohemian Massif. Tomek et al. (1997) presented the interpretation of many reflections along the 9HR profile and discussed their possible origin. Positions of seismic interfaces were estimated, however, no information about seismic velocities was provided. The conclusion was that the Moldanubian unit yielded significantly different patterns from both the Teplá-Barrandian and Saxothuringian units. A detailed review of older deep seismic sounding experiments in the Bohemian Massif was given by Málek et al. (2001).

In 2000, the CELEBRATION (Central European Lithospheric Experiment Based on Refraction) took place (Guterch et al., 2003). The profile C09 was nearly parallel to the deep seismic sounding profile and to our TBR-MOX profile. Data from C09 were processed by several methods and the results in the form of 1-D or 2-D models can be found in Hrubcová et al. (2005) and Růžek et al. (2007). Hrubcová et al. (2005) suggested a clear Moho discontinuity for the Teplá-Barrandian and Moldanubian units, but she proposed a laminated lower crust structure for the Saxothuringian unit. Růžek et al. (2007) suggested a $2 \mathrm{D} \mathrm{v}_{\mathrm{p}}$ model for the whole C09 profile and as the most interesting feature he highlighted a very low-velocity anomaly reaching through the whole crust down to a depth of just a few kilometers above the Moho beneath the Moldanubian unit.

All these studies concerned only P-wave velocity distributions. There is a relative lack of information about S-wave velocities in the region of our interest. Only a few studies concerning S-waves have been performed. Malinowski (2005) used the CELEBRATION data for the analysis of short-period Rayleigh waves; he studied S-wave velocities, however, he estimated the crustal structure for only the upper $2 \mathrm{~km}$ along the C09 profile. Plešinger et al. (1991) gave the crustal shear wave velocity estimation from surface waves for the KHC-MOX profile (also used in our study, see below). In recent years, the receiver 
function method has also been used to study the Bohemian Massif. Wilde-Piórko et al. (2005) published detailed $\mathrm{v}_{\mathrm{s}}$ models under several stations in the Bohemian Massif obtained by the receiver function technique. For the Saxothuringian unit, the depth of the Moho was estimated to be $28-31 \mathrm{~km}$. In the Moldanubian unit, the Moho was estimated to be at a depth of 33$34 \mathrm{~km}$. In the paper by Heuer et al. (2006) the depth of the Moho was again estimated to be deeper beneath the Moldanubian unit (35-40 km), shallower beneath the Teplá-Barrandian unit (30-33 km) and closest to the surface beneath the Saxothuringian unit $(27-31 \mathrm{~km})$. Another study dealing with receiver functions by Heuer et al. (2007) revealed a whole lithosphere separation between the Moldanubian unit on the one hand, and the Teplá-Barrandian and Saxothuringian units on the other. The thickness of the lithosphere of the Moldanubian unit was estimated as $130 \mathrm{~km}$ while the lithosphere of the other two units was found to be only 80-90 km thick. These results were discussed by Heuer et al. (2007) with respect to the previous study revealing the depths of the Moho - both the depths of the Moho and of the lithosphere-asthenosphere boundary are deeper for the Moldanubian unit than for the western units.

Kolínský and Brokešová $(2007,2008)$ estimated Western Bohemia uppermost crust $\mathrm{v}_{\mathrm{s}}$ and group velocities using shortperiod surface waves. 1D models of several Love wave profiles crossing the region proved the lateral heterogeneity of the given area, and Rayleigh wave tomography provided a detailed image of Western Bohemia region's upper crust. For an overview of other studies concerning only the Western Bohemia region, part of the Saxothuringian unit, refer to the introduction of the paper by Kolínský and Brokešová (2007).

The above mentioned studies concerned only a limited depth range (Malinowski, 2005); they estimated the structure only locally, beneath a single station (Wilde-Piórko, 2005; Heuer et al., 2006, 2007) or they concerned only a limited area (Kolínský and Brokešová, 2007 and 2008). In contrast, our present study estimates S-wave velocities along whole profiles with better depth resolution than achieved by Plešinger et al. (1991). Moreover, in our study, we focus on the differences between the three particular geological units.

There were several stations available for the given region which were situated along profiles coinciding (in terms of influence zones) with the surface wave paths from three selected Aegean Sea earthquakes (close to the coast of Turkey), see Fig. 1. Fig. 2 shows a detailed map of the region of interest with station names indicated. The stations form two long profiles: Tábor (TBR) - Moxa (MOX) and Kašperské Hory (KHC) - MOX.

Although there are a number of papers on phase velocity determination using advanced techniques and considering also non-plane-wave character of the waves (McMechan and Yedlin (1981), Gabriels et al. (1987) - shallow seismic profiling using higher modes; Stange and Friederich (1993) - regional network phase velocity inversion; Forbriger (2003a, 2003b) - theory for shallow seismic wave-field inversion), we adopt the well known two-station approach assuming the plane-wave propagation to determine the phase velocities of surface waves. This is justified not only by long epicentral distance, but also by the use of sufficiently long-period waves which are not influenced by local lateral heterogeneities. Such approach is reported in many papers (Nafe and Brune, 1960 - global phase velocity study from an Alaska earthquake; McEvilly, 1964 phase velocities across Central US; Levshin et al,. 1992 - regional phase velocities across Asia; Mitra et al., 2006 - phase velocity in the south Indian shield). We do not attempt to develop a new method of phase velocity measurement; we rather use the classical and simple one to obtain new information about the structure of the Bohemian Massif. We present some modifications of the classical interstation phase-velocity measurement: we correct the dispersion curves for the true backazimuth propagation instead of using directly the geometrical great circle paths, and we also use the two-station method for stations which are much closer to one another with respect to the wavelengths than it is usually used in the literature.

\section{Data}

During 2005, three temporary stations TBR (Tábor), HAJ (Háje) and NEC (Nečtiny) (Fig. 2) were operated by the Institute of Rock Structure and Mechanics, Academy of Sciences of the Czech Republic, forming a southeast-northwest oriented profile across the Bohemian Massif. Guralp CMG-40T seismometers with a flat response characteristic up to $30 \mathrm{~s}$ were used at all 
stations. At the same time, two permanent Streckeisen STS-2 (120 s) stations KHC (Kašperské hory) and NKC (Nový Kostel)

(Fig. 2) were operated by the Geophysical Institute, Academy of Sciences of the Czech Republic, as a part of the Czech Regional Seismic Network. We also add one permanent STS-2 MOX (Moxa) station from Germany. For the investigation of

crustal velocities along the profiles, we selected three shallow Aegean Sea (Fig. 1, Table 1) earthquakes with clear Love wavegroups.

These three earthquakes have similar magnitudes and are located close to each other. They are processed independently and only the period ranges that yield the same results for all three earthquakes are taken into account. This procedure ensures highly reliable results. Three events close to one another may eliminate random errors; however, systematic errors caused, for example, by multipathing cannot be removed using this approach.

\section{Table 1}

\begin{tabular}{|c|l|c|l|l|l|l|l|}
\hline Location & Mw & Date & Origin time & Epic. longitude & Epic. latitude & Depth & Label \\
\hline Aegean Sea & 5.7 & $2005 / 10 / 17$ & $05: 45: 16.0$ & $26.50^{\circ} \mathrm{E}$ & $38.13^{\circ} \mathrm{N}$ & $8 \mathrm{~km}$ & $\mathrm{e} 17 \mathrm{a}$ \\
\hline Aegean Sea & 5.8 & $2005 / 10 / 17$ & $09: 46: 53.9$ & $26.50^{\circ} \mathrm{E}$ & $38.20^{\circ} \mathrm{N}$ & $10 \mathrm{~km}$ & $\mathrm{e} 17 \mathrm{~b}$ \\
\hline Aegean Sea & 5.9 & $2005 / 10 / 20$ & $21: 40: 04.1$ & $26.75^{\circ} \mathrm{E}$ & $38.15^{\circ} \mathrm{N}$ & $10 \mathrm{~km}$ & $\mathrm{e} 20$ \\
\hline
\end{tabular}

Basic information about the events used in this study; according to the USGS National Earthquake Information Center PDE Catalog (2006).

The events were selected to fit approximately the great circle delineated by the stations. This gives us a rare opportunity to study the structure directly within the selected profiles and not averaged over various azimuths.

Backazimuths of great circles and epicentral distances of each event-station pair computed by the method of Novotný and Málek (2002) are given in Table 2. However, considering the wavelengths of surface waves, we use the theory of influence zones given by Yoshizawa and Kennett (2002). These zones represent the region of surface wave coherence. Figs 1 and 2 show simplified influence zones corresponding to the laterally homogeneous structure for the most distant station MOX. The simplified influence zones are presented as ellipses with major axes oriented along the epicenter-station (geometrical) paths.

\section{Table 2}

\begin{tabular}{|l|l|l|l|l|l|l|l|l|l|l|l|l|}
\hline \multicolumn{1}{|c|}{ Profile } & \multicolumn{9}{|c|}{ TBR-MOX profile } & \multicolumn{4}{c|}{ KHC-MOX profile } \\
\hline \multicolumn{1}{|c|}{ Station } & \multicolumn{1}{|c|}{ TBR (Guralp) } & \multicolumn{2}{c|}{ HAJ (Guralp) } & \multicolumn{2}{c|}{ NEC (Guralp) } & \multicolumn{2}{c|}{ NKC (STS-2) } & \multicolumn{3}{c|}{ KHC (STS-2) } & MOX (STS-2) \\
\hline loc. ${ }^{\circ} \mathrm{E} /{ }^{\circ} \mathrm{N}$ & 14.6484 & 49.4129 & 14.0490 & 49.6747 & 13.1686 & 49.9774 & 12.4480 & 50.2331 & 13.5782 & 49.1309 & 11.6161 & 50.6461 \\
\hline event & dist. & backaz. & dist. & backaz. & dist. & backaz. & dist. & backaz. & dist. & backaz. & dist. & backaz. \\
\hline e17a & 1571.5 & 138.5 & 1622.1 & 137.6 & 1690.0 & 136.1 & 1746.4 & 135.0 & 1602.1 & 134.9 & 1820.8 & 134.1 \\
\hline e17b & 1565.0 & 138.3 & 1615.7 & 137.4 & 1683.6 & 135.9 & 1740.1 & 134.8 & 1595.8 & 134.7 & 1814.4 & 134.0 \\
\hline $\mathrm{e} 20$ & 1581.7 & 137.7 & 1632.5 & 136.9 & 1700.7 & 135.4 & 1757.3 & 134.4 & 1613.3 & 134.2 & 1831.7 & 133.5 \\
\hline
\end{tabular}

Locations of stations, epicentral distances $(\mathrm{km})$ and backazimuths (degrees) for event-station pairs.

We consider two long profiles KHC-MOX $(219 \mathrm{~km})$ and TBR-MOX $(249 \mathrm{~km})$. The latter is further divided into four subprofiles: TBR-HAJ $(50.7 \mathrm{~km})$, HAJ-NEC (68.0 km), NEC-NKC (56.4 km) and NKC-MOX (74.3 km), see Fig. 2. The lengths of profiles are measured as differences between epicentral distances of the corresponding stations along great circles. In case of the three earthquakes, these lengths vary in the range of $\pm 0.1 \mathrm{~km}$, as implied by Table 2 .

In Fig. 2, we see that all stations are situated within the influence zone for the 12 s period for station MOX; hence, the theory supports the possibility of using these stations for relative phase velocity measurements with MOX station from $12 \mathrm{~s}$ to longer periods. The maximum difference in azimuths as seen from the epicenter (geometrical backazimuths) to stations is found for the pair TBR and MOX and its value is $2.1^{\circ}$, see Table 3. This meets well the condition proposed by Levshin et al. (1992) according to which the azimuths should differ by less than $6^{\circ}$. 
Table 3

\begin{tabular}{|l|l|l|l|l|l|l|l|l|l|l|l|l|l|}
\hline & \multicolumn{4}{|c|}{ Azimuths of propagation from epicenter $\left({ }^{\circ}\right)$} & \multicolumn{4}{c|}{ Differences of azimuths $\left({ }^{\circ}\right)$} \\
\hline Event & TBR & HAJ & NEC & NKC & KHC & MOX & TBR-MOX & TBR-HAJ & HAJ-NEC & NEC-NKC & NKC-MOX & KHC-MOX \\
\hline e17a & 326.7 & 326.3 & 325.4 & 324.9 & 323.9 & 324.6 & 2.13 & 0.46 & 0.81 & 0.57 & 0.28 & 0.73 \\
\hline e17b & 326.6 & 326.1 & 325.3 & 324.7 & 323.7 & 324.4 & 2.11 & 0.46 & 0.81 & 0.57 & 0.28 & 0.75 \\
\hline e20 & 326.2 & 325.7 & 325.0 & 324.4 & 323.4 & 324.2 & 2.02 & 0.44 & 0.78 & 0.55 & 0.26 & 0.81 \\
\hline
\end{tabular}

Azimuths of propagation from epicenters and mutual differences of these azimuths for all three events and all six station pairs.

The largest difference between interstation backazimuths and geometrical backazimuths was found for the NEC station on the HAJ-NEC profile $\left(18^{\circ}\right)$. It is significantly larger than is usually accepted. For instance, Mitra et al. (2006) used only station pairs, whose mutual paths differed from the geometrical backazimuths by less than $7^{\circ}$. In these studies, interstation and epicentral distances could be compared; in our study, however, there is a significant difference between interstation distances $(\sim 50 \mathrm{~km})$ and the epicentral distances $(\sim 1700 \mathrm{~km})$. Therefore, despite the $18^{\circ}$ difference, our stations are still well aligned.

The above-mentioned findings as well as quality of data available imply that it is reasonable to use the dispersion curves in the period range of $12 \mathrm{~s}$ to $40 \mathrm{~s}$ in case of the TBR-MOX profile and of $12 \mathrm{~s}$ to $73 \mathrm{~s}$ in case of the KHC-MOX profile. Dispersion measurement was performed also for shorter periods down to $8 \mathrm{~s}$, however, shorter wavelengths suffered by higher scattering and were not used for the final inversion.

We present an analysis of phase velocities of Love waves measured at a broad period range. The reason why we did not used also the Rayleigh waves is that they suffer by much higher scattering and incoherence and clear phase velocities can be found only in the period range of 15-25 s. Moreover, Love wave propagation depends only on $\mathrm{v}_{\mathrm{s}}$. Thus the inverse problem is qualitatively simpler when inverting for only one quantity distribution $\left(\mathrm{v}_{\mathrm{s}}\right)$.

\section{Love wave analysis}

As it is usual in studies dealing with phase velocity, first we need to analyze the records to isolate the fundamental mode (Dziewonski et al., 1972; Yoshida and Suetsugu, 2004). We follow the procedure described by Kolínský and Brokešová (2007). The classical method of Fourier transform-based multiple filtering was applied to analyze the dispersive records. We use non-constant relative resolution filtering; see Dziewonski et al. (1969). Examples of estimating the optimum coefficient for controlling the width of the filters can be found in Levshin et al. (1972 and 1992). In the present paper, we use the linear dependence of the filter coefficient on period, see Kolínský (2004). As symmetric Gaussian filters are applied to a generally asymmetric spectrum, the frequencies which prevail in the filtered spectra do not match the central frequencies of the filters (Dziewonski et al., 1972). We solve this by estimating the instantaneous frequency (Levshin et al., 1989) which is computed using the analytical signal corresponding to each filtered quasi-monochromatic signal. The modulus of the analytical signal represents an envelope of the filtered signal, and we use the amplitudes of these envelopes to pick up the fundamental mode. Selecting the dispersion ridge of the fundamental mode is described in Kolínský and Brokešová (2007). We use the criterion of continuity - among all ridges found in the spectrogram, the desired fundamental mode is selected to present a smooth curve regardless of the amplitudes. We obtain group velocity dispersion curves, which are visually compared to decide whether the records are suitable for further relative phase velocity measurements.

After we select the wavegroup corresponding to the fundamental mode in each harmonic component, we truncate each of these harmonic components by a window centered at the envelope maximum with cosine taper on both window sides. Parameters are set so that the taper smoothes two periods around one period which is kept unchanged. Because we need to compare the records from different stations, we use the same width of filters in the frequency domain and the same width of truncating windows in the time domain for all stations to ensure the coherency of the records. We create a filtered seismogram containing only the Love wavegroup by summing these truncated filtered signals. This filtered seismogram is shown together 
with the original record in Fig. 3a. The traditional peak and trough technique of manual estimation of phase velocity is demonstrated in this figure. The difference between the spectra of raw records and filtered fundamental modes is shown in Figs $3 \mathrm{~b}$ and $3 \mathrm{c}$. The filtered fundamental modes display similar waveforms in the time domain and similar shapes of spectra in the frequency domain. The amplitudes of signals differ by about 10 percent.

\section{Phase velocity measurement}

Methods of cross-correlation and other time domain methods were discussed, for example, by Nafe and Brune (1960), McEvilly (1964), Wielandt et al. (1987). We use the correlation of filtered and truncated quasi-monochromatic components measured at two stations. Fig. 4 shows the coincidence of the harmonic components of stations HAJ and NEC shifted in time by $17 \mathrm{~s}$. This rough time shift was introduced according to the Fig. 3a. In Fig. 4, we see that the time shift is set correctly in the period range around 19-20 s in this example, but for other periods, the waveforms are not so well correlated. We used the $\mathrm{L}_{1^{-}}$ norm to estimate the similarity of two signals while mutually shifting the signals sample by sample. We thus directly find the time difference for each filtered component and we compute the phase velocity. The central period of multiple filtering is used for matching the respective components at two stations. However, since the instantaneous period of the filtered signals differs from the central, we use the average of these instantaneous periods from both stations to plot the phase velocity dispersion curve. These instantaneous periods are estimated for the quasi-monochromatic signal at the time corresponding to the envelope maximum of the signal, as mentioned in the Love wave analysis.

The number of wavelengths between the stations is checked to obtain the correct value of the time shift. We consider three possible dispersion curves - one for the global minimum of $\mathrm{L}_{1}$-norm and two for the neighboring local minima. These three dispersion curves correspond to the different cycles of waves which were correlated. We select the proper curve according to the fact that the phase velocity is expected to be around $4.0 \mathrm{~km} / \mathrm{s}$ for periods around $20 \mathrm{~s}$.

\section{Backazimuth correction}

As the Earth is not laterally homogeneous, surface waves do not propagate precisely along great circles. Therefore, the real backazimuth differs from the geometrical one.

The dispersion curves for long profiles KHC-MOX and TBR-MOX are expected to be similar as both profiles are situated inside the same influence zone, and the geological structure of the Bohemian Massif is not expected to be very different for both profiles. We want to test, whether mutual differences of the measured dispersion curves can be explained by considering the true backazimuths. We assume that the difference between the two dispersion curves measured along the two long profiles KHC-MOX and TBR-MOX is caused only by errors in the backazimuth. Under this assumption, the true backazimuth $\beta(\omega)$ and phase velocity $c(\omega)$ for the given frequency $\omega$ can be obtained by solving the system of equations:

$$
t_{i}(\omega)=\frac{R_{i} \cos \left(\alpha_{i}-\beta(\omega)\right)}{c(\omega)} \quad i=1 . . n-1
$$

where $t_{i}$ is the time difference, $R_{i}$ is the geographical distance between the stations, $\alpha_{i}$ is the interstation backazimuth and $n$ is the number of stations. All three quantities refer to the $i$-th and the last station. In our case $n=3$, so we have two equations and two unknown parameters $\beta(\omega)$ and $c(\omega)$. 


\section{Inversion}

During the inversion process, we followed the procedure described by Kolínský and Brokešová (2007). The isometric method is used, which is a fast inverse algorithm developed by Málek et al. (2005) and tested by Málek et al. (2007). Typical problems, which are effectively solved by the isometric method, are weakly non-linear problems with tens of parameters and complicated forward modeling. The basic underlying idea of the isometric method is to postulate the distance in the model space in such a way that the model and data spaces are isometric, i.e. the distances in both spaces have the same measure. As all model-data vector pairs are used many times in successive iterations, the number of the forward problem computations is minimized. It is not necessary to deal with derivatives. Therefore, this method is suitable for the inversion of dispersion curves.

The forward problem is solved by the modified Thomson-Haskell matrix method; see Proskuryakova et al. (1981). Dispersion curves are found in a 1-D layered model above a halfspace with constant values of $\mathrm{v}_{\mathrm{s}}$ and density in the individual layers and the halfspace.

During the inversion, the phase velocity dispersion curve is computed many times and the distance between theoretical and measured dispersion points (misfit function) is minimized. The thicknesses of layers are set manually. In the present study, we consider layers 2 or $4 \mathrm{~km}$ thick, which ensures a good resolution for finding the properties of the velocity distribution and keeps the number of parameters reasonable.

We seek one parameter in each layer: the shear wave velocity. Density is kept unchanged during the inversion as well as the thicknesses of layers. Density values are introduced according to the gravity measurements along the 9HR profile, see Švancara and Chlupáčová (1997). Surface wave propagation does not depend on density significantly; the density effect is of an order of magnitude lower than the effect of the shear wave velocities. Any unrealistic oscillation of the velocities is avoided by constrains of the velocity difference between neighboring layers. The number of parameters with respect to the number of measured dispersion points and starting models were discussed in Kolínský and Brokešová (2007). The results of inversion do not depend on the starting model; however, we may save computational time by setting the starting model appropriately. Since the inversion of the dispersion curves is highly non-unique, even for the same starting parameters, different results are obtained. We compute the inversion problem twenty times, and as a result we obtain the mean value of twenty velocities in each layer with its standard deviation. For details refer to Kolínský and Brokešová (2007), where tests of the inversion reliability and a discussion on the resolution of the procedure can be found.

\section{Synthetic tests of the analysis and inversion}

We propose three synthetic tests to verify our methodology. The first of them benchmarks the surface wave analysis procedure itself, the second one tests the dispersion curve inversion method, and the third one tests both surface wave analysis and dispersion curve inversion together.

The goal of the first test is to convince ourselves that our methodology is able to determine the correct phase velocity dispersion curve. For this test we consider a theoretical velocity model and compute the corresponding synthetic seismograms and exact synthetic dispersion curve. We then determine the dispersion curve from the synthetic seismograms and compare the determined dispersion curve with the theoretical one. We assume a 1D shear wave velocity model (Fig. 5, left panel) consisting of 10 layers over a halfspace. This model is chosen to resemble the model obtained by inverting the group velocity dispersion curve estimated from the Aegean Sea earthquake measured at station TBR, and hence it may be considered as a realistic model for the real surface wave path. We compute two synthetic seismograms by the discrete wavenumber method, Bouchon (1981), corresponding to stations TBR and MOX, see Fig. 5, upper right panels. These synthetics are processed as if they were real records (i.e. as described in the previous section) to determine the phase velocity dispersion curve. In Fig. 5 (upper right panels), the filtered fundamental modes are shown as gray lines. We compute an exact synthetic phase velocity dispersion curve between TBR and MOX, see Fig. 5 (lower right panel), using the modified matrix method for computing the dispersion curve, Proskuryakova et al. (1981). The lower right panel of the figure shows the comparison of the synthetic dispersion curve 
and that determined by our methodology. We see that both curves match each other with an average difference of $\pm 0.02 \mathrm{~km} / \mathrm{s}$. Thus, this test verifies our analysis procedure on a synthetic example.

To prove the reliability of our phase velocity inversion method, we propose another test. We compute an exact synthetic dispersion curve for a considered theoretical structure using the modified matrix method by Proskuryakova et al. (1981), invert it, and compare the determined structure with the considered one. Note that no synthetic seismograms are involved in this test. We again assume a 1D shear wave velocity model; see Fig. 6, left panel. The layer distribution (number and thicknesses) is the same as in the previous test of the surface wave analysis method, compare it to Fig. 5, left panel. However, the velocity values are different. Here we consider a low velocity zone (LVZ) to test whether the inversion is capable of retrieving it. Note that this velocity distribution with LVZ is similar to the real velocity model found for the HAJ-NEC profile. We compute the synthetic phase velocity dispersion curve for this model and select only a limited number of dispersion points to resemble the real measurement; see Fig. 6, right panel, diamonds. We estimate the error of each dispersion point to be $\pm 0.06 \mathrm{~km} / \mathrm{s}$ (see error bars in Fig. 6, right panel) based on the quality of the real measured data at our disposal (see next sections). We propose a suitable number and thicknesses of layers for the inversion - this system is the same in the test as it is in the real data processing. Generally, layer thicknesses differ from those used in the considered theoretical model, because we do not know them in the real case.

We perform twenty inversions so that for each inversion, each of the dispersion points has a random error in the range of $\pm 0.06 \mathrm{~km} / \mathrm{s}$. These randomly disturbed dispersion curves (indicated only implicitly by the error bars in Fig. 6) enter the inversion procedure. The twenty dispersion curves, shown as grey lines in Fig. 6, right panel, correspond to the structures found by the inversion according to the lowest misfit function criterion. We see that, despite relatively large error bars, all the found curves fit the original (exact) synthetic curve well. This is due to the inversion procedure being sufficiently robust and insensitive to the local disturbance of the dispersion curve. We see that for longer periods, the curves exhibit larger scattering. We treat the twenty resultant shear wave velocity models exactly in the same way as the real data-based models: we compute the mean value for each layer, and we show this mean shear wave velocity distribution with its standard deviation in the left panel of Fig. 6 in comparison with the considered theoretical model. We see that, except for the sharp discontinuities at depths of 7 and $33 \mathrm{~km}$, the considered model is within the range of the standard deviation of the mean determined velocity distribution. LVZ is a bit smoothed in our test. It is a general feature of the procedure, that it smoothes sharp discontinuities and LVZs, as proved by many tests. In never produces a false discontinuity or LVZ.

The third test combines both previous tests, i. e. we consider a 1D theoretical structure, compute synthetic seismograms and determine the dispersion curve in the same way as if the seismograms were measured. We treat this dispersion curve in exactly the same way as explained in the previous test. We invert the curve and compare the determined structure with the considered theoretical one. More specifically, we use the same velocity distribution including the LVZ as in the previous test, see the blue dashed line in Fig. 7, left plot. For stations TBR and MOX, the synthetic seismograms are computed by the discrete wavenumber method. The phase velocity dispersion curve between both stations is determined, see the crosses in Fig. 7, right plot. The dispersion curve is disturbed randomly to obtain twenty curves processed by the inversion. These curves are inverted to obtain shear wave velocity models (gray lines represent their standard deviations) and their mean, see solid red line in Fig. 7 , left plot. As expected, since the structures considered in the second and in the third tests are the same, we obtained similar results, i. e. the original structure is retrieved within the range of the standard deviation. However, only the third test works exactly in the way we also treat the real data.

\section{Results}

Figures 8 and 9 show the fundamental modes and their spectra of three earthquakes for the KHC-MOX and TBR-MOX profiles, respectively. The records are mutually shifted in time to fit the most significant amplitudes approximately - the Airy 
phases. Both signals and spectra are corrected using the instrumental transfer function. We see that the records are well coherent and suitable for phase velocity measurements.

Fig. 10 shows reduced travel-time curves for the TBR-MOX profile for a set of periods and for the reduction velocity of $4.0 \mathrm{~km} / \mathrm{s}$. This means that the travel-time curve with this velocity would be represented by a horizontal line. The travel times correspond to the amplitude maximum of the signal envelope for each period so that the figure shows the group velocity dispersion. The reduced travel time is considered relatively to the arrival of the $40 \mathrm{~s}$ wave at station TBR. Generally, short periods are slower and longer periods are faster than the reduction velocity. This figure enables us to check the quality of the analysis intuitively. The travel-time curves form a smooth system of lines, which do not intersect each other. We see also differences of the curves for the individual sub-profiles. For example, longer periods for the NEC-NKC sub-profile display faster wave propagation than for the other sub-profiles. The phase velocity measurement for each sub-profile is capable of revealing these differences precisely.

Two panels displaying phase velocity dispersion curves are shown in Fig. 11. The curves measured for each earthquake for the two long profiles KHC-MOX and TBR-MOX are shown in Fig. 11a as light-colored lines and their averages as darkcolored lines. Fig. 11b concerns the TBR-MOX profile; we see four sets of dispersion curves measured for each of the four sub-profiles using the records of all three events.

We also compute the average curve for the whole TBR-MOX profile obtained as the average of four sub-profile curves (Fig. 11a, orange line) and we compare this average curve with the original curve measured for the whole TBR-MOX profile (Fig. 11a, dashed dark green line). They are almost identical, which confirms that the surface wave paths for the long profile and its sub-profiles are similar.

Let us discuss in more detail the behavior of the dispersion curves in Fig. 11b. The curves display significant differences; for periods longer than $25 \mathrm{~s}$ their scatter is lower than that for shorter periods. In general, Love wave phase velocity curves should monotonically increase with period for 1D structures. However, the dispersion curves for the four sub-profiles in Fig. 11b have complicated shapes with decreasing velocity in some period intervals. This behavior cannot be explained by velocity measurement errors: the dispersion curves are smooth, they are determined independently for three earthquakes, and the undulations of the curves have amplitudes which exceed the measurement error. One possible explanation of these undulations is that they are due to the deviations of surface wave propagation paths from the great circle (geometrical backazimuth). As waves of different periods reflect from heterogeneities of different scales, different backazimuths for arrivals of different periods are expected.

The paper by Wilde-Piórko et al. (2005) suggests that the structure (derived from the receiver functions) in the direction perpendicular to our profiles does not change considerably. Moreover, the geological unit boundaries in the region of interest are also nearly perpendicular to our profiles. This allows us to hypothesize that the geological structure of the Bohemian Massif does not vary much from the KHC-MOX profile to the TBR-MOX profile so that both profiles should display a similar dispersion curve. We further assume that the differences between the dispersion curves are due to the off-great circle propagation. Let us find the backazimuths for which the curves become the same (we use the TBR/KHC-MOX label for it below).

Fig. 12 shows corrected backazimuths computed according to equation (1). In Fig. 2 we depict the range of true backazimuths for station MOX as two bold dashed blue lines; these lines represent the highest and the lowest corrected backazimuth values from Fig. 12 .

In Fig. 12, we see a smooth, generally monotonic dependence of the corrected backazimuth of the limited range of $10^{\circ}$ (from $131^{\circ}$ to $141^{\circ}$ ) with respect to period, however, small variations appear. For shorter periods, surface waves arrive at the Bohemian Massif under greater backazimuths (more from the south) than for the longer periods. Fig. 12 shows also both the inter-station backazimuths and geometrical backazimuths (ranging from $134^{\circ}$ to $138^{\circ}$, see Table 2 ) of the great circle paths between the Aegean Sea and the respective stations (these are averages of the three events). We see that, for all profiles, the 
corrected backazimuth for shorter periods is larger while for the longer periods it is smaller than the geometrical backazimuth. Consequently, the corrected backazimuth can be either more or less distant from the inter-station backazimuth than the geometrical. If it is less distant, the apparent inter-station distance (with respect to the wave propagation direction) increases and approaches the true inter-station distance and, therefore, the corrected phase velocity increases, and vice versa.

As Fig. 11a implies (comparison of the sub-profile averaged curve and the long-profile TBR-MOX curve), that the averaged propagation direction in the four sub-profiles is similar to the propagation direction in the long profile, and hence we are justified in applying the true backazimuth corrections found for the long profile to the sub-profiles.

Fig. 13a provides the corrected TBR/KHC-MOX dispersion curve. The reason, why the corrected TBR/KHC-MOX curve is so similar to the measured KHC-MOX curve, is that, by chance, the corrected backazimuth range is centered almost at the KHC-MOX inter-station backazimuth. Looking at the corrected backazimuth range in Fig. 2, we see that station KHC is situated nearly in the middle of this range with respect to station MOX.

Fig. 13b shows the corrected curves for the four sub-profiles from Fig. 11b. The corrected dispersion curves in Fig. 13b are steeper as the phase velocity becomes lower for shorter periods and higher for longer periods. This is due to the fact that all the inter-station backazimuths for the TBR-MOX profile and all its sub-profiles are smaller than the geometrical backazimuths. Contrary to this, for the KHC-MOX profile (Fig. 13a), the inter-station backazimuth is larger than the geometrical, and hence the corrected TBR/KHC-MOX dispersion curve rises less with period than the uncorrected curve for the KHC-MOX profile.

Fig. 13 shows that the dispersion curve undulations are slightly smoothed (except for the TBR-HAJ sub-profile) in comparison with the measured ones. The variations of the corrected backazimuth-period dependence (Fig. 12) affect especially the HAJ-NEC sub-profile curve in such a way that the most pronounced undulation is diminished.

\section{Table 4}

\begin{tabular}{|c|c|c|c|c|c|c|c|c|c|c|c|}
\hline & & \multicolumn{2}{|c|}{ TBR/KHC-MOX } & \multicolumn{2}{c|}{ TBR-HAJ } & \multicolumn{2}{c|}{ HAJ-NEC } & \multicolumn{2}{|c|}{ NEC-NKC } & \multicolumn{2}{c|}{ NKC-MOX } \\
\hline $\mathrm{d}$ & $\mathrm{h}$ & $\mathrm{v}_{\mathrm{s}}$ & $\mathrm{rms}$ & $\mathrm{v}_{\mathrm{s}}$ & $\mathrm{rms}$ & $\mathrm{v}_{\mathrm{s}}$ & $\mathrm{rms}$ & $\mathrm{v}_{\mathrm{s}}$ & $\mathrm{rms}$ & $\mathrm{v}_{\mathrm{s}}$ & $\mathrm{rms}$ \\
\hline 2 & 0 & 2.94 & 0.133 & 2.94 & 0.109 & 2.95 & 0.138 & 2.88 & 0.152 & 2.88 & 0.105 \\
\hline 2 & 2 & 3.41 & 0.215 & 3.45 & 0.154 & 3.48 & 0.208 & 3.27 & 0.169 & 3.24 & 0.168 \\
\hline 4 & 4 & 3.68 & 0.135 & 3.69 & 0.152 & 3.79 & 0.103 & 3.44 & 0.137 & 3.52 & 0.133 \\
\hline 4 & 8 & 3.69 & 0.084 & 3.80 & 0.118 & 3.86 & 0.095 & 3.55 & 0.081 & 3.67 & 0.125 \\
\hline 4 & 12 & 3.69 & 0.100 & 3.77 & 0.092 & 3.80 & 0.082 & 3.58 & 0.124 & 3.71 & 0.112 \\
\hline 4 & 16 & 3.69 & 0.120 & 3.77 & 0.094 & 3.74 & 0.078 & 3.68 & 0.157 & 3.74 & 0.083 \\
\hline 4 & 20 & 3.73 & 0.121 & 3.76 & 0.116 & 3.72 & 0.087 & 3.79 & 0.199 & 3.75 & 0.106 \\
\hline 4 & 24 & 3.81 & 0.162 & 3.77 & 0.120 & 3.67 & 0.122 & 3.97 & 0.172 & 3.78 & 0.112 \\
\hline 4 & 28 & 3.87 & 0.169 & 3.82 & 0.136 & 3.70 & 0.163 & 4.22 & 0.152 & 3.84 & 0.182 \\
\hline 4 & 32 & 4.15 & 0.187 & 4.06 & 0.265 & 3.91 & 0.200 & 4.40 & 0.185 & 3.98 & 0.220 \\
\hline 4 & 36 & 4.34 & 0.149 & 4.44 & 0.179 & 4.29 & 0.226 & 4.58 & 0.137 & 4.29 & 0.223 \\
\hline Halfspace & 40 & 4.73 & 0.072 & 4.74 & 0.070 & 4.87 & 0.055 & 4.66 & 0.042 & 4.64 & 0.060 \\
\hline
\end{tabular}

Mean shear wave velocities for all five profiles TBR/KHC-MOX, TBR-HAJ, HAJ-NEC, NEC-NKC and NKC-MOX, see also Fig. 14. Explanations: $d=$ thickness of layer $(\mathrm{km}), h=$ depth of the layer's upper boundary $(\mathrm{km}), v_{s}=$ mean shear wave velocity $(\mathrm{km} / \mathrm{s}), \mathrm{rms}=$ standard deviation $(\mathrm{km} / \mathrm{s})$.

Since the dispersion curve undulations still remain after the backazimuth correction, another explanation is needed. One of the possible reasons is that we observe a coupling of Love wave modes, probably due to reflection and diffraction at heterogeneities, where the fundamental mode is converted into higher modes. A detailed theory may be found in the paper by Maupin (2007). Waves of the same period can then propagate with different velocities, interfere with one another, and may cause the undulations we observe. Since, in general, inversion produces smooth dispersion curves, we expect the misfit between measured and inverted curves to be greater for profiles where undulations are more pronounced.

We inverted the corrected dispersion curves for all five profiles: TBR/KHC-MOX, TBR-HAJ, HAJ-NEC, NEC-NKC and NKC-MOX using the methodology described above. Since the period range $8-40 \mathrm{~s}$ was measured, we provided inversions for four different period ranges starting with $8,10,12$ and $15 \mathrm{~s}$. We than compared the resultant shear wave velocity distributions. 
Since the models differed for the inversions taking account short periods ( 8 and $10 \mathrm{~s}$ ) and since there was no change in the models for the inversion starting from 12 and $15 \mathrm{~s}$, we decided to use the period range $12-40 \mathrm{~s}$ for the final inversion. The results are summarized in Table 4 and Figs 14a-e. Crosses (lower panels) represent the backazimuth-corrected dispersion curves. Only the average corrected curve is shown for each profile, however, for inversion, twenty different curves with random errors ranging $\pm 0.06 \mathrm{~km} / \mathrm{s}$ around this corrected curve are used exactly in the same way as in the tests described previously. Twenty dispersion curves obtained by the inversion are shown as gray lines. We see that all twenty curves are almost identical although the corresponding twenty velocity models differ. This is due to the non-uniqueness of the dispersion curve inversion - the same dispersion curve can be obtained from different velocity models. The resultant mean structure is shown as the red line and its standard deviations as gray lines in each upper panel of Fig. 14.

\section{Table 5}

\begin{tabular}{|c|c|c|c|c|c|c|c|}
\hline & & & & & inversion & combined \\
TEST \\
Mean rms (km/s) (shear wave velocity) & 0.137 & 0.134 & 0.130 & 0.142 & 0.136 & 0.129 & 0.128 \\
\hline Mean fit error (km/s) (phase velocity) & 0.019 & 0.058 & 0.049 & 0.031 & 0.028 & 0.010 & 0.013 \\
\hline
\end{tabular}

Upper line presents deviations computed as an average of the rms deviations for all layers in each profile; see Table 4. Bottom line presents the error computed as the average distance between the measured dispersion curve and the twenty inverted dispersion curves; see Fig. 14, lower panels. The five measured profiles are complemented by the same information for the test structures from Figs 6 and 7.

We obtain five velocity structures for the five profiles which, in general, differ from each other. The standard deviations of the estimated structures are nearly the same for all the profiles, see Table 5 (upper line), although the scattering of the twenty inverted dispersion curves varies considerably from profile to profile, Table 5 (lower line). The lowest dispersion curve error of $0.019 \mathrm{~km} / \mathrm{s}$ (the best misfit) is obtained for the TBR/KHC-MOX profile. Its dispersion curve is of a smooth monotonic shape, and the inversion thus matches it almost perfectly for the whole period range. Contrary to this, the worst misfit is obtained for the most undulated dispersion curve corresponding to the TBR-HAJ profile $(0.058 \mathrm{~km} / \mathrm{s})$. Note, that, as expected, the test examples are characterized by significantly smaller misfits.

Fig. 14 allows us to compare the structures along the individual profiles. It shows certain common features (high-gradient subsurface layers, no sharp Moho discontinuity) as well as distinct qualitative differences (LVZ).

The two eastern TBR-HAJ and HAJ-NEC sub-profiles, crossing the Moldanubian and Teplá-Barrandian units (Fig. 2), display LVZ in the middle crust (Fig. 14c and d). The high gradient in the depth range of 32-40 km can be interpreted as a manifestation of the Moho discontinuity. This blurring of the discontinuity over several layers can also be seen in the test example in Figs 6 and 7, and we cannot thus distinguish whether it is a real structural feature or only an artifact of the method. The third NEC-NKC sub-profile crossing the Eger Rift (boundary between the Teplá-Barrandian and Saxothuringian units, Fig. 2) displays a nearly constant increase of velocity across the whole crust (Fig. 14b). No gradient increase is seen there. The last sub-profile, the most western NKC-MOX, crossing the Saxothuringian unit (Fig. 2), is characterized by nearly constant $\mathrm{v}_{\mathrm{s}}$ in the middle crust (Fig. 14a). Contrary to the two eastern TBR-HAJ and HAJ-NEC sub-profiles, the NKC-MOX sub-profile displays a much weaker gradient increase spread over a larger depth interval (20 km to $40 \mathrm{~km})$. This range is too wide to be interpreted as an inversion artifact. Hence, the two western sub-profiles show no indication of the Moho.

The long TBR/KHC-MOX profile shows nearly constant $\mathrm{v}_{\mathrm{s}}$ in the middle crust below the high-gradient in the upper $4 \mathrm{~km}$ (Fig. 14e). Its structure is qualitatively similar to that obtained for the NKC-MOX sub-profile, however, in this case, the high gradient in the narrower depth range of $32-40 \mathrm{~km}$ can be interpreted as an indication of the Moho discontinuity. 


\section{Discussion}

We have found a $\mathrm{v}_{\mathrm{s}}$ distribution for both long profiles and the short sub-profiles. The agreement of the averaged sub-profile

dispersion curve with the TBR-MOX long-profile one (Fig. 11) suggests that local lateral inhomogeneities do not influence the propagation azimuths of the waves in the given period range.

We would like to verify the results by comparison with the results published by other authors, if available. Note that we can only compare our results with studies yielding structures representing whole profiles and not with those representing local structures beneath individual stations (e.g., obtained by the receiver function method).

Concerning the long profiles, the only comparison possible is for the KHC-MOX profile. There are no suitable studies for comparison with our TBR-MOX profile. In Fig. 15 we present a comparison with the $\mathrm{v}_{\mathrm{s}}$ structure by Plešinger et al. (1991). Plešinger's KHC-MOX $\mathrm{v}_{\mathrm{s}}$ structure (dashed blue) is estimated for the crust and upper mantle using the surface wave period range from 10 to $100 \mathrm{~s}$. We show the result for the backazimuth-corrected TBR/KHC-MOX dispersion curve (Fig. 13a) as the bold red line, and as the bold green line we also show the result obtained using the same methodology for the original KHCMOX profile (with no backazimuth correction, Fig. 11a). This original KHC-MOX profile corresponds geographically exactly to the Plešinger's KHC-MOX profile. We see that the differences between our KHC-MOX and the TBR/KHC-MOX profiles are very small and both match Plešinger's model well. The most striking difference between our and his study concerns the upper 7 kilometers. In our study, the subsurface structure is characterized by a considerably lower velocity which is compensated by higher velocities in other layers. The explanation is that Plešinger's model has a small number of layers for the whole crust and, therefore, it cannot be as detailed. The total depth of our first three layers corresponds to the thickness of the first layer in Plešinger's model. The velocity averaged over our first three layers roughly corresponds to the velocity in his first layer. In the middle crust, both our and his measurements yield very similar velocities. Another feature is Plešinger's distinct discontinuity (Moho) at a depth of $32 \mathrm{~km}$, which is replaced by a gradient zone in our study, since our approach is not capable of revealing sharp discontinuities, see also the synthetic test section. On the other hand, it is questionable whether Plešinger's distinct Moho is a real structural feature and not only an artifact of his method (model parameterization).

As regards the four sub-profiles, only a few $\mathrm{v}_{\mathrm{s}}$ models are available for comparison, e. g., Malinowski (2005). He found a quasi-2D structure from surface waves along the C09 profile, see Fig. 2, roughly coinciding with our segmented TBR-MOX profile. Due to the short periods considered in his study, his results cover only depths down to $2 \mathrm{~km}$. Malinowski refers to the lower sub-surface velocities in the Saxothuringian unit (western part of the C09 profile) than in the Moldanubian unit (eastern part of the C09 profile). Our result give nearly the same velocities around $2.90-2.95 \mathrm{~km} / \mathrm{s}$ in the $2 \mathrm{~km}$ uppermost layer for all four sub-profiles what is in agreement with the velocity range of $2.5-3.4 \mathrm{~km} / \mathrm{s}$ given by Malinowski for the same depth.

Other studies dealing with profile measurements in the region of our sub-profiles concern P-waves only and, therefore, any comparison with these results is very questionable, since $\mathrm{v}_{\mathrm{s}}$ structural features may not even qualitatively be manifested in the $v_{p}$ structure. For example, the presence of the LVZ in the $v_{s}$ model does not imply that the LVZ must be present also in the $v_{p}$ distribution. On the other hand, the LVZ in $\mathrm{v}_{\mathrm{p}}$ model indicates that similar behavior can be seen also in the $\mathrm{v}_{\mathrm{s}}$ structure. This is due to the physical processes which can cause the decrease of both $v_{p}$ and $v_{s}$ at the same time, or the decrease of $v_{s}$ only. For example partial melting would affect $\mathrm{v}_{\mathrm{s}}$ more seriously than the $\mathrm{v}_{\mathrm{p}}$. Beránek (1971) found the LVZ in the $\mathrm{v}_{\mathrm{p}}$ distribution using reflection for Moldanubian and Teplá-Barrandian units. Since we have found the LVZ for the same two units for $\mathrm{v}_{\mathrm{s}}$ as well, we think that our results may be realistic in this respect. Růžek at al. (2007) also found very low values down to the lower crust only for the Moldanubian unit, but report increasing $v_{p}$ for the other two units. However, the fact that they did not find the LVZ in the $\mathrm{v}_{\mathrm{p}}$ distribution in the Teplá-Barrandian unit does not imply that the LVZ cannot be found in the $\mathrm{v}_{\mathrm{s}}$ distribution.

Another feature qualitatively comparable both in $\mathrm{v}_{\mathrm{p}}$ and $\mathrm{v}_{\mathrm{s}}$ structures is the presence of the Moho discontinuity. Hrubcová et al. (2005) found evidence of a distinct Moho at the depth of $39 \mathrm{~km}$ for the Moldanubian unit and $35 \mathrm{~km}$ for the TepláBarrandian unit. As discussed above, our methodology is unable to determine a sharp Moho. Both their Moho depths fall 
within the range of the high-gradient zone found in our study for these two units. For the Saxothuringian unit, they suggest a laminated lower crust structure without any clear Moho discontinuity, which is in agreement with our results for this unit.

Comparing the shear wave velocity distributions of the four sub-profiles (Fig. 14), we see that three of them, which are fully included in one of the units, present similar features. TBR-HAJ profile (Moldanubian unit) reveals nearly constant shear wave velocities in a broad range of depths from 8 to $32 \mathrm{~km}$ with slight LVZ. The non-increasing shear wave velocity is probably a consequence of the old sedimentary composition of the whole unit. Even the Moldanubian unit was highly metamorphosed, it still keeps its nearly homogeneous composition from the Proterozoic age. HAJ-NEC profile (TepláBarrandian unit) is characterized by significant LVZ in the middle crust, what would correspond to its only slightly (if at all) metamorphosed sedimentary composition. Its LVZ is more pronounced than it is in the Moldanubian unit, but both units follow nearly the same general shear wave velocity distribution what confirms their similar age. The depths $4-12 \mathrm{~km}$ are characterized by slightly lower velocities in the Moldanubian than in the Teplá-Barrandian unit, what may be caused by the intrusions which penetrated the Moldanubian unit during the Variscan age (Central Bohemian Pluton). NKC-MOX profile (Saxothuringian unit) has the same shear wave velocities as both latter units from the depths of $16 \mathrm{~km}$ down to the upper mantle, however, its upper crust velocities in the depth range of $2-16 \mathrm{~km}$ are even lower than those of the Moldanubian, what may be again caused by the Variscan intrusions.

NEC-NKC profile, which crosses the Teplá-Barrandian and Saxothuringian unit border, is distinctively different. Shear wave velocities along the whole depth range differs significantly from those for the other three profiles. They are lower in the upper crust $(4-16 \mathrm{~km})$ and higher in the lower crust and upper mantle $(16-40 \mathrm{~km})$. The contact between Teplá-Barrandian and Saxothuringian unit is formed by the Eger Rift, which is filled by Tertiary sediments and by products of Neogenic volcanism. The profile also crosses the area of seismic swarm activity around the village of Nový Kostel (near the station NKC). The hypocenter depths of the swarm activity are around $8-12 \mathrm{~km}$ and the origin of the swarms are believed to be caused by fluid redistribution. The region is also known for higher heat flow. Both the presence of fluids and higher temperature would correspond to lower shear wave velocities observed in that depth range. Higher velocities in the lower crust are a consequence of nearly missing Moho, what is possibly caused by updoming of the upper mantle, as described by Heuer et al. (2006).

Although none of the above mentioned studies made by other authors contradicts our findings, we are aware that the found 1D structures represent only averaged velocity distributions along profiles. Moreover, several important phenomena have been omitted both by us and by the other authors as well. For example, attenuation or anisotropy has not been taken into account. The reason is that there is a lack of information. Anisotropy of the region of interest is discussed in the paper by Plomerová et al. (2007) who reveal different patterns of teleseismic P-wave anisotropy beneath the Moldanubian, Teplá-Barrandian and Saxothuringian units. However, these results concern only the upper mantle and no conclusions are made for the crustal structure we are interested in.

\section{Conclusion}

The phase velocity dispersion curves of Love waves, generated by moderate regional earthquakes, are analyzed to estimate $\mathrm{v}_{\mathrm{s}}$ in the crust of the western part of the Bohemian Massif. The reliability of both measurement and inversion is benchmarked by tests. Two profiles crossing three main geological units of the Bohemian Massif are investigated. A comparison of our $\mathrm{v}_{\mathrm{s}}$ models with those previously published for the same region shows a generally good agreement.

We propose detailed 1D models of $\mathrm{v}_{\mathrm{s}}$ for both the long TBR/KHC-MOX profile as well as for the sub-profiles of the TBRMOX profile, where only $v_{p}$ were measured in the past. We found that the dispersion curves of the sub-profiles are nonmonotonic. Such curves cannot be interpreted in detail using forward modeling as their shape is complicated and hence cannot be described fully by the inversion. We suggest that the undulations of phase velocity curves are caused by different backazimuths of propagation with respect to period and we find the corrected backazimuths using the two long profiles KHC- 
MOX and TBR-MOX as the reference profiles. The dispersion curves corrected for the true backazimuths have slightly smaller undulations for some sub-profiles and become steeper. However, the undulations cannot be explained by the corrected backazimuth fully. The inversion of undulated dispersion curves yields larger misfit errors in comparison with the smooth

TBR/KHC-MOX long profile curve, but standard deviations of sub-profile $\mathrm{v}_{\mathrm{s}}$ are of the same order as for the inversion of the long profile. The two eastern parts of the TBR-MOX profile (TBR-HAJ and HAJ-NEC sub-profiles) display LVZ at depths of 12 to $28 \mathrm{~km}$ what is connected with their old sedimentary origins. The Moho discontinuity is manifested along the two eastern sub-profiles and is missing along the two western sub-profiles, what may be caused by the upper mantle updoming. NEC-NKC profile shear wave velocities of the Eger Rift are significantly different than those of the other three profiles crossing consolidated units of the Bohemian Massif. Sub-surface (first layer) shear wave velocity is nearly the same for all four subprofiles (around $2.9 \mathrm{~km} / \mathrm{s}$ ) suggesting that the uppermost crust is not influenced much by old Variscan tectonic processes.

\section{Acknowledgements}

This research was supported by Grants No. A300460602 and No. A300460705 of the Grant Agency of the Academy of Sciences of the Czech Republic, by Grant No. 205/06/1780/A of the Czech Science Foundation and by the Institute's Research Plan No. A VOZ30460519. This work was also supported in part by the Ministry of Education, Youth and Sports of the Czech Republic, Project No. MSM0021620860. Data from two of the stations used in this study were kindly provided by Jan Zedník of the Czech Regional Seismic Network, Geophysical Institute, Academy of Sciences of the Czech Republic, v.v.i. We thank Oldřich Novotný for programs and consultations concerning matrix method computations. We are grateful to Monika WildePiórko for providing her results. Two of the figures were made using Generic Mapping Tools by Wessel and Smith (1998). We are grateful to RWE Transgas, s.r.o., for providing the data from station HAJ. We also thank two anonymous reviewers for their suggestive comments.

\section{References}

Beránek, B., 1971: Study of the velocity conditions in the Earth's crust in the regions of the Bohemian Massif and the Carpathian system along international profiles VI and VII, Stud. Geophys. Geod., 15, 316-330.

Beránek, B., Mayerová, M., Zounková, M., Guterch, A., Materzok, R. and Pajchel, J., 1973: Results of deep seismic sounding along international profile VII in Czechoslovakia and Poland, Stud. Geophys. Geod., 17, $205-217$.

Beránek, B. and Zounková, M., 1977: Investigations of the Earth's crust in Czechoslovakia using industrial blasting, Stud. Geophys. Geod., 21, 273-280.

Bouchon, M., 1981: A simple method to calculate Green's functions for elastic layered media, Bull. Seism. Soc. Am. 71, 959971.

Cháb, J., Šrámek, J., Pokorný, L., Chlupáčová, M., Manová, M., Vejnar, Z., Waldhausrová, J. and Žáček, V., 1997: Geological interpretation of major regional units - the Teplá-Barrandian Unit, in: Vrána, S. and Štědrá, V. (eds): Geological Model of Western Bohemia Related to the KTB Borehole in Germany, Czech Geological Survey, Prague, 80-104.

Dziewonski, A., Bloch, S. and Landisman, M., 1969: A Technique for the Analysis of Transient Seismic Signals, Bull. Seism. Soc. Am., 59, 427-444.

Dziewonski, A., Mills, J. and Bloch, S., 1972: Residual Dispersion Measurement - a New Method of Surface-Wave Analysis, Bull. Seism. Soc. Am., 62, 129-139.

Forbriger, T., 2003a: Inversion of shallow-seismic wavefields. Part 1: Wavefield transformation, Geophys. J. Int., 153, 719734.

Forbriger, T., 2003b: Inversion of shallow-seismic wavefields. Part II: Infering subsurface properties from wavefield transforms, Geophys. J. Int., 153, 735-752.

Gabriels, P., Snieder, R. and Nolet, G., 1987: In situ measurements of shear wave velocity in sediments with higher-mode Rayleigh waves, Geophys. Prospect., 35, 187-196.

Guterch, A., Grad, M., Keller, G. R., Posgay, K., Vozár, J., Špičák, A., Brückl, E., Hajnal, Z., Thybo, H., Selvi, O. and CELEBRATION 2000 Experiment Team, 2003: CELEBRATION 2000 Seismic Experiment. Stud. Geophys. Geod., 47, 659-669.

Heuer, B., Geissler, W. H., Kind, R. and Kämpf, H., 2006: Seismic evidence for asthenospheric updoming beneath the western Bohemian Massif, central Europe, Geophys. Res. Lett., 33, L05311, doi: 10.1029/2005GL025158.

Heuer, B., Kämpf, H., Kind, R. and Geissler, W. H., 2007: Seismic evidence for whole lithosphere separation between Saxothuringian and Moldanubian tectonic units in central Europe, Geophys. Res. Lett., 34, L09304, doi: 10.1029/2006GL029188. 
Hrubcová P., Środa P., Špičák A., Guterch A., Grad M., Keller G. R., Brueckl E., and Thybo H., 2005: Crustal and uppermost mantle structure of the Bohemian Massif based on CELEBRATION 2000 data, J. Geophys. Res., 110, B11305.

Kolínský, P., 2004: Surface Wave Dispersion Curves of Eurasian Earthquakes: the SVAL Program, Acta Geodyn. Geomater., 2 (134), 165-185.

Kolínský, P. and Brokešová, J., 2007: The Western Bohemia Uppermost Crust Shear Wave Velocities from Love Wave Dispersion, Journal of Seismology, 11, 101-120.

Kolínský, P. and Brokešová, J., 2008: The Western Bohemia Uppermost Crust Rayleigh Wave Tomography, Acta Geodyn. Geomater. Vol. 5, No. 1, (149), 5-17.

Levshin, A., Pisarenko, V. F., Pogrebinsky, G. A., 1972: On a Frequency-Time Analysis of Oscillations, Ann. Geophys., 28, 211-218.

Levshin, A. L., Yanovskaya, T. B., Lander, A. V., Bukchin, B. G., Barmin, M. P., Ratnikova, L. I. and Its, E. N., 1989: Interpretation of Surface Wave Observations - Frequency-time Analysis, in: Keilis-Borok, V. I. (ed.): Seismic Surface Waves in a Laterally Inhomogeneous Earth, Kluwer Academic Publishers, Dordrecht/Boston/London, 153-163.

Levshin, A. L., Ratnikova, L. and Berger, J., 1992: Peculiarities of Surface-Wave Propagation across Central Eurasia. Bull. Seism. Soc. Am., 82, 2464-2493.

Málek, J., Brož, M., Fischer, T., Horálek, J., Hrubcová, P., Janský, J., Novotný, O., Růžek, B. and the CELEBRATION working group, 2001: Seismic Measurements along Short Profiles in Western Bohemia During the CELEBRATION 2000 Experiment, Acta Montana, series A, 18 (121), 15-28.

Málek, J., Horálek, J. and Janský, J., 2005: One-dimensional qP-Wave Velocity Model of the Upper Crust for the West Bohemia/Vogtland Earthquake Swarm Region, Stud. Geophys. Geod., 49, 501-524.

Málek, J., Růžek, B., Kolář, P., 2007: Isometric method: efficient tool for solving non-linear inverse problems. Stud. Geophys. Geod., 51, 469-491.

Malinowski, M., 2005: Analysis of Short-Period Rayleigh Waves Recorded in the Bohemian Massif Area During CELEBRATION 2000 Experiment, Stud. Geophys Geod., 49, 485-500.

Maupin, V., 2001: A multiple-scattering scheme for modelling surface wave propagation in isotropic and anisotropic threedimensional structures, Geophys. J. Int., 146, 332-348.

Maupin, V., 2002: The amplitude of the Love-Rayleigh discrepancy created by small-scale heterogeneities, Geophys. J. Int., $150,58-64$.

Maupin, V., 2007: Introduction to mode coupling methods for surface waves, in: Wu, R.-S. and Maupin, V. (eds.): Advances in wave propagation in heterogeneous Earth, Advances in geophysics, vol. 48, chapter 2, Elsevier, 127-155.

McEvilly, T. V., 1964: Central U.S. crust-upper mantle structure from Love and Rayleigh wave phase velocity inversion, Bull. Seism. Soc. Am., 54, 1997-2015.

McMechan, G.A. and Yedlin, M.J., 1981: Analysis of dispersive waves by wave field transformation, Geophysics, 46, 869874.

Mitra, S., Priestley, K., Gaur, V. K. and Rai, S. S., 2006: Shear-Wave Structure of the South Indian Lithosphere from Rayleigh Wave Phase-Velocity Measurements, Bull. Seism. Soc. Am., 96, 1551-1559.

Mlčoch, B., Schulmann, K., Šrámek, J., Manová, M., Pokorný, L., Fiala, J. and Vejnar, Z., 1997: Geological interpretation of major regional units - the Saxothuringian zone, in: Vrána, S. and Štědrá, V. (eds): Geological Model of Western Bohemia Related to the KTB Borehole in Germany, Czech Geological Survey, Prague, 51-61.

Nafe, J. E. and Brune, J. N., 1960: Observation of phase velocity for Rayleigh waves in the period range 100 to 400 seconds, Bull. Seism. Soc. Am., 50, 427-439.

NEIC (National Earthquake Information Center), 2006: PDE Catalog, Washington, US, neic.usgs.gov.

Novotný, O. and Málek, J., 2002: Note of the direct computation of geodetic distances and azimuths on an ellipsoid of revolution, Acta Montana, 22 (129), 75-78.

Plešinger, A., Neunhöfer, H. and Wielandt, E., 1991: Crust and upper mantle structure of the Bohemian Massif from the dispersion of seismic surface waves, Stud. Geophys. Geod., 35, 184-195.

Plomerová, J., Achauer, U., Babuška, Vl., Vecsey, L. and BOHEMA working group, 2007: Upper mantle beneath the Eger Rift (Central Europe): plume or asthenosphere upwelling?, Geophys. J. Int., 169, 675-682.

Proskuryakova, T.A., Novotný, O. and Voronina, E. V., 1981: Studies of the Earth's Structure by the Surface-Wave Method (Central Europe) (Izuchenie stroeniya Zemli metodom poverkhnostnykh voln (Tsentral'naya Evropa) (Nauka, Moscow 1981), in Russian, 92 pp.

Růžek B., Hrubcová P., Novotný M., Špičák A., Karousová O., 2007. Inversion of travel times obtained during active seismic refraction experiments CELEBRATION 2000, ALP 2002 AND SUDETES 2003, Stud. Geophys. Geod., 51, 141-166.

Stange, S. and Friederich, W., 1993: Surface wave dispersion and upper mantle structure beneath southern Germany from joint inversion of network recorded teleseismic events, Geophys. Res. Lett., 20(21), 2375-2378.

Švancara, J. and Chlupáčová, M, 1997: Gravimetry / Density model of geological structure along the profile 9HR /, in: Vrána, S. and Štědrá, V. (eds): Geological Model of Western Bohemia Related to the KTB Borehole in Germany, Czech Geological Survey, Prague, 32-35.

Tomek, Č., Dvořáková, V. and Vrána, S., 1997: Geological interpretation of the 9HR and 503M seismic profiles in Western Bohemia / The 9HR profile, in: Vrána, S. and Štědrá, V. (eds): Geological Model of Western Bohemia Related to the KTB Borehole in Germany, Czech Geological Survey, Prague, 43-50. 
Vrána, S., Šrámek, J., Pokorný, L., Manová, M., Chlupáčová, M., 1997: Geological interpretation of major regional units the Moldanubian Zone, in: Vrána, S. and Štědrá, V. (eds): Geological Model of Western Bohemia Related to the KTB Borehole in Germany, Czech Geological Survey, Prague, 104-123.

Wessel, P., and Smith, W. H. F., 1998: New, improved version of generic mapping tools released, Eos Trans. AGU, 79 (47), 579.

Wielandt, E., Sigg, A., Plešinger, A. and Horálek, J. (1987), Deep Structure of the Bohemian Massif from Phase Velocities of Rayleigh and Love Waves, Stud. Geophys. Geod., 31, 1-7.

Wilde-Piórko, M., Saul, J. and Grad, M., 2005: Differences in the Crustal and Uppermost Mantle Structure of the Bohemian Massif from Teleseismic Receiver Functions, Stud. Geophys. Geod., 49, 85-107.

Yoshida, Y. and Suetsugu, D., 2004: Lithospheric Thickness Beneath the Pitcairn Hot Spot Trail as Inferred from Rayleigh Wave Dispersion, Physics of the Earth and Planetary Interiors, 146, 75-85.

Yoshizawa, K. and Kennett, B. L. N., 2002: Determination of the Influence Zone for Surface Wave Paths, Geophys. J. Int., $149,440-453$. 
Figures with Captions

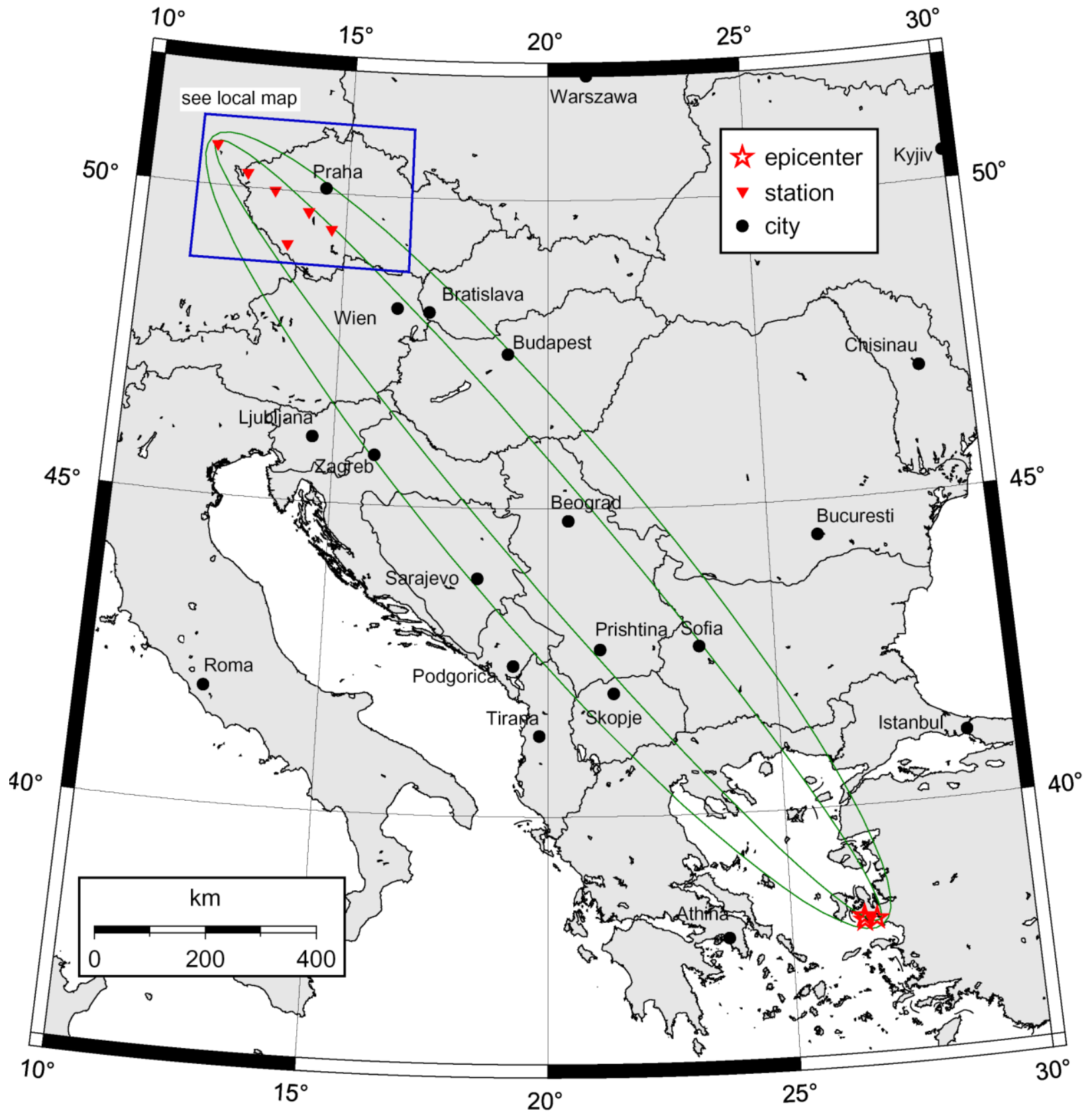

Fig. 1

Surface wave paths across Europe shown in terms of influence zones for 12 and $40 \mathrm{~s}$ period surface waves. The epicenters of three Aegean Sea earthquakes are situated close to one another. 


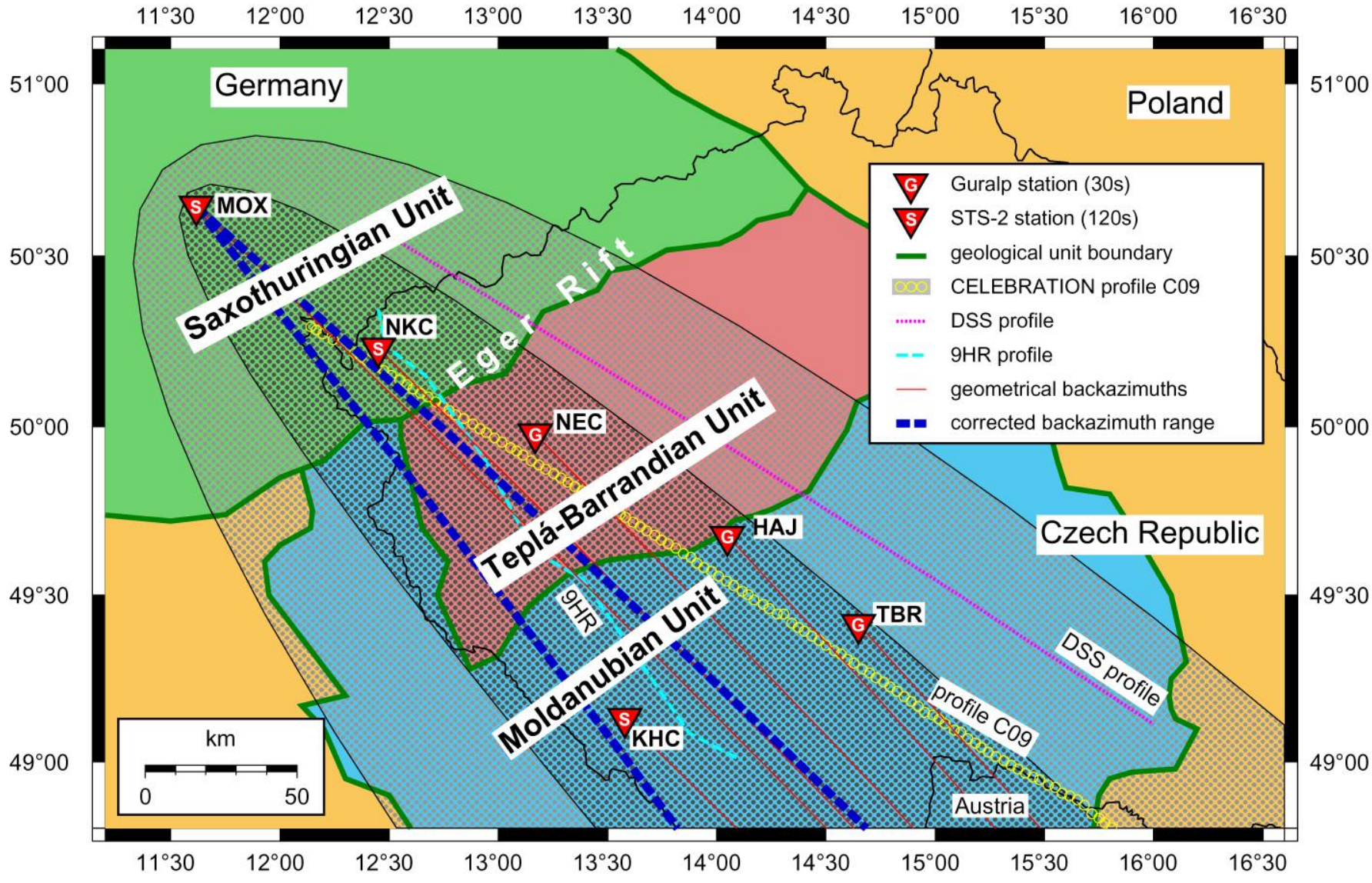

Fig. 2

Five stations TBR, HAJ, NEC, NKC and MOX forming the $260 \mathrm{~km}$ long profile and two stations KHC and MOX forming the $220 \mathrm{~km}$ long profile are shown in the context of the main geological units (Saxothuringian unit by green, Teplá-Barrandian unit by red and Moldanubian unit by blue, other units not used in this study are yellow) and former refraction and deep seismic sounding experiments. The influence zones for the most distant station MOX for 12 and 40 s period surface waves are drawn for one of the three Aegean Sea earthquakes used in this study (e20 - 2005/10/20). Bold blue dashed line shows the corrected backazimuth range for different periods (see Fig. 12). 


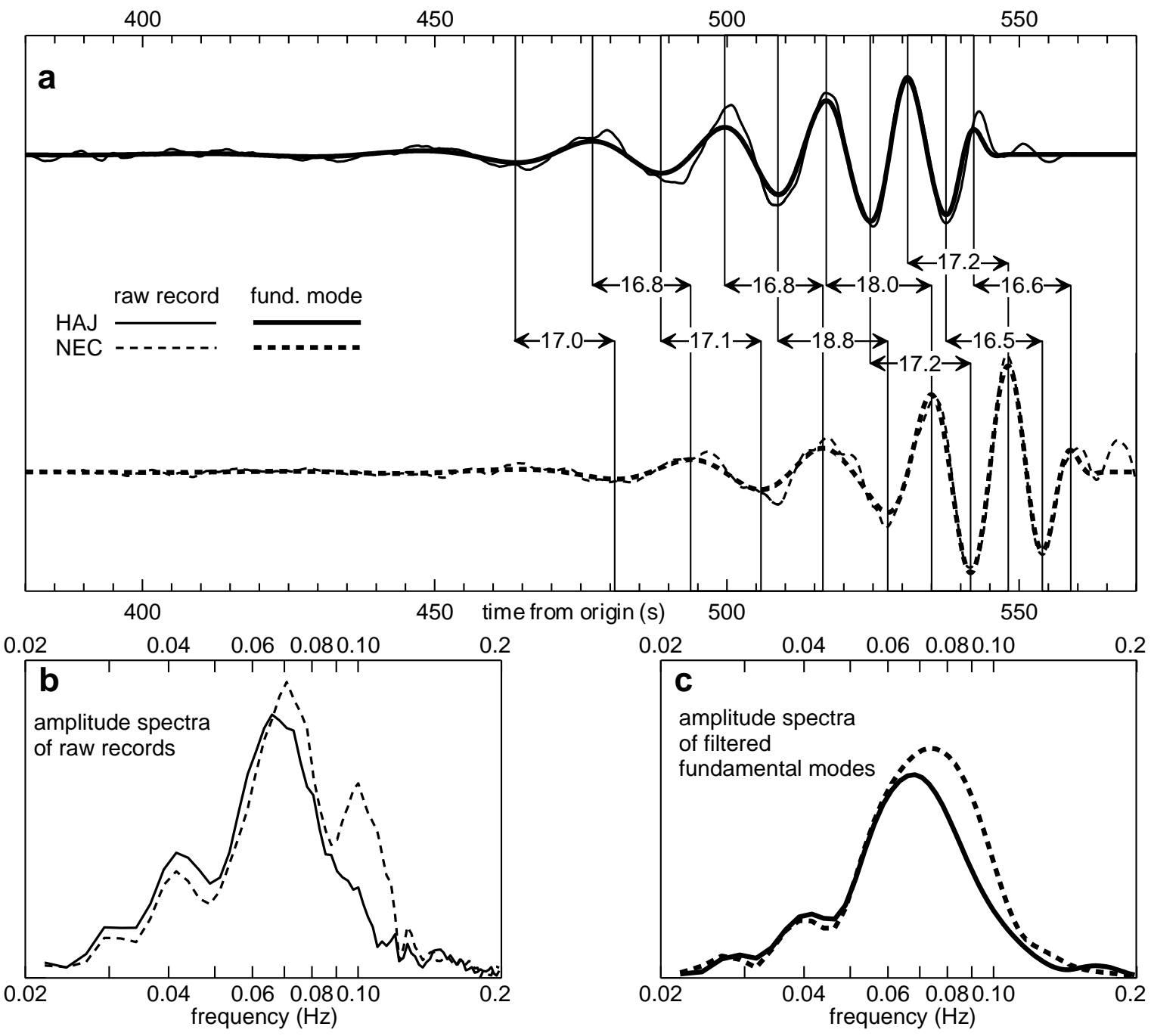

Fig. 3

Raw records at two stations are shown in comparison with the filtered fundamental modes (a). Fundamental modes are drawn for the period range $12-40 \mathrm{~s}$. The peak and trough technique sketch shows a mutual time shift of the corresponding filtered records. Amplitude spectra for both stations and both raw records (b) and fundamental modes (c) are shown. The instrumental transfer function is applied both in the time and frequency domain. 


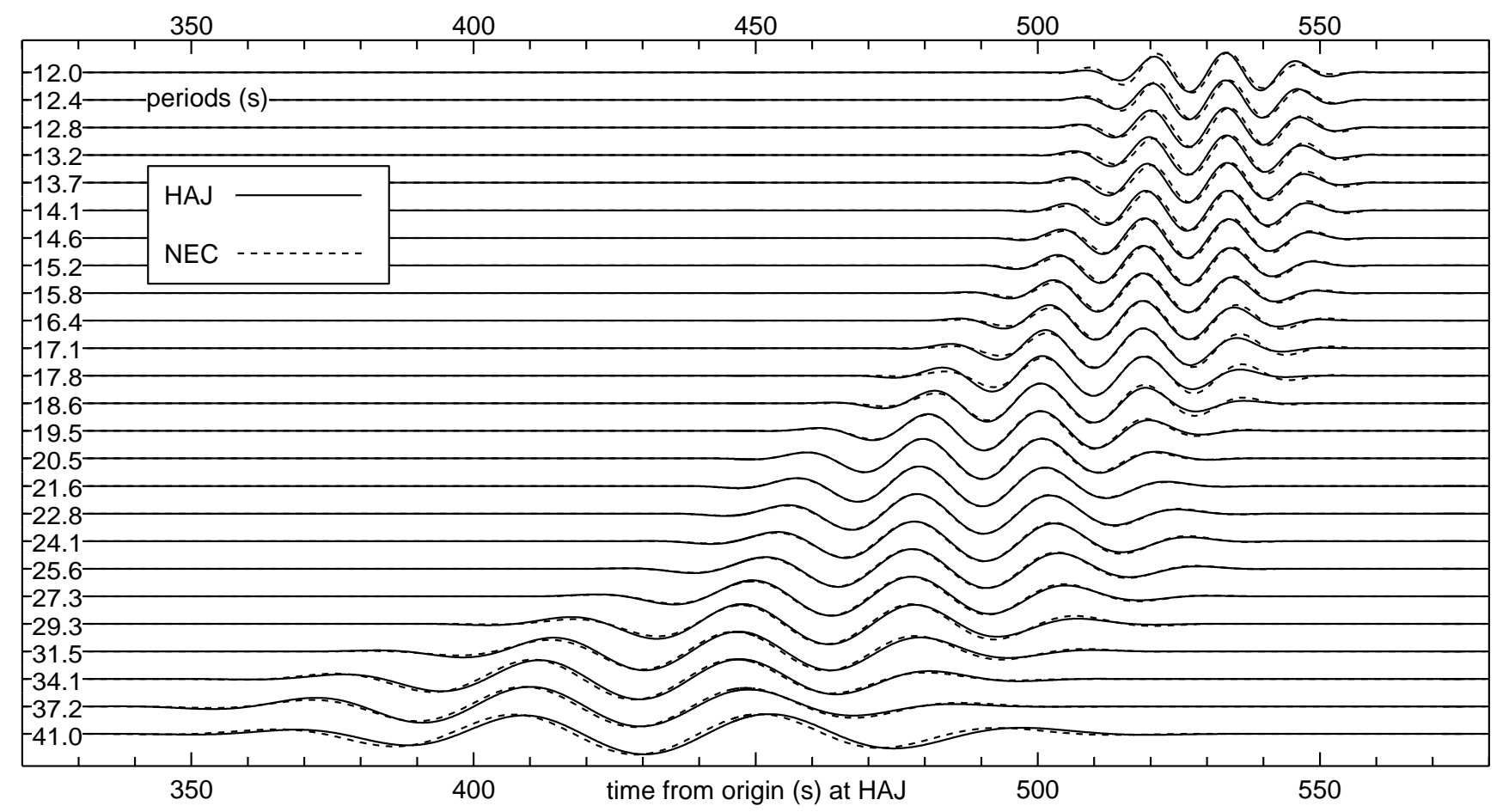

\section{Fig. 4}

Fundamental mode harmonic components of the same two station as in Fig. 3. Record from the NEC station is shifted by $17 \mathrm{~s}$ in time to correspond roughly to the HAJ station record. We see well-correlated signals with slight mutual shifts, which are used to estimate the phase velocities. The amplitudes are normalized. 


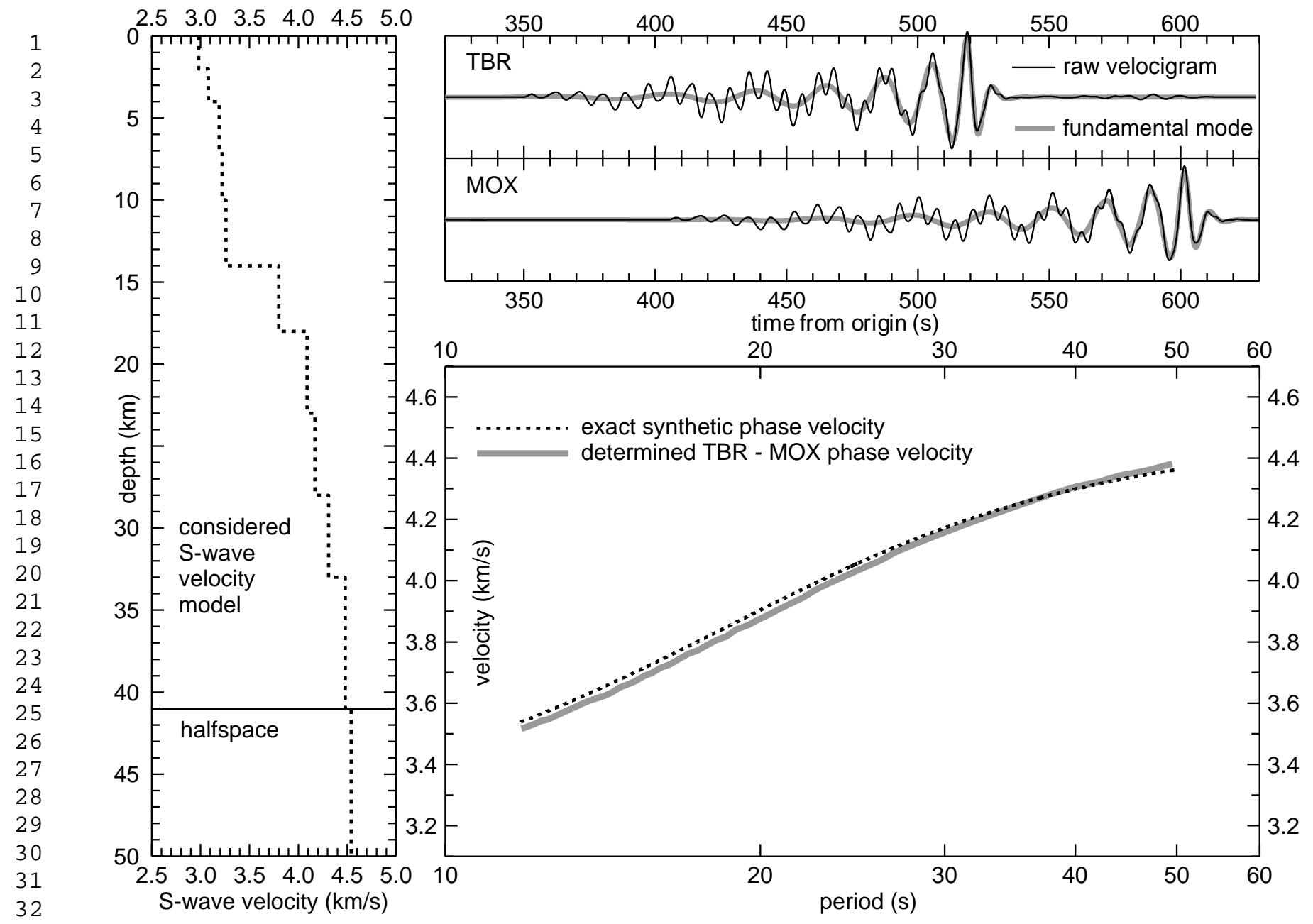

Fig. 5

Surface wave analysis test. Left panel represents the considered shear wave velocity model. Upper right panel shows synthetic seismograms with fundamental modes estimated by the frequency-time analysis. Lower right panel shows a comparison of synthetic (exact) and determined phase velocity dispersion curves. 

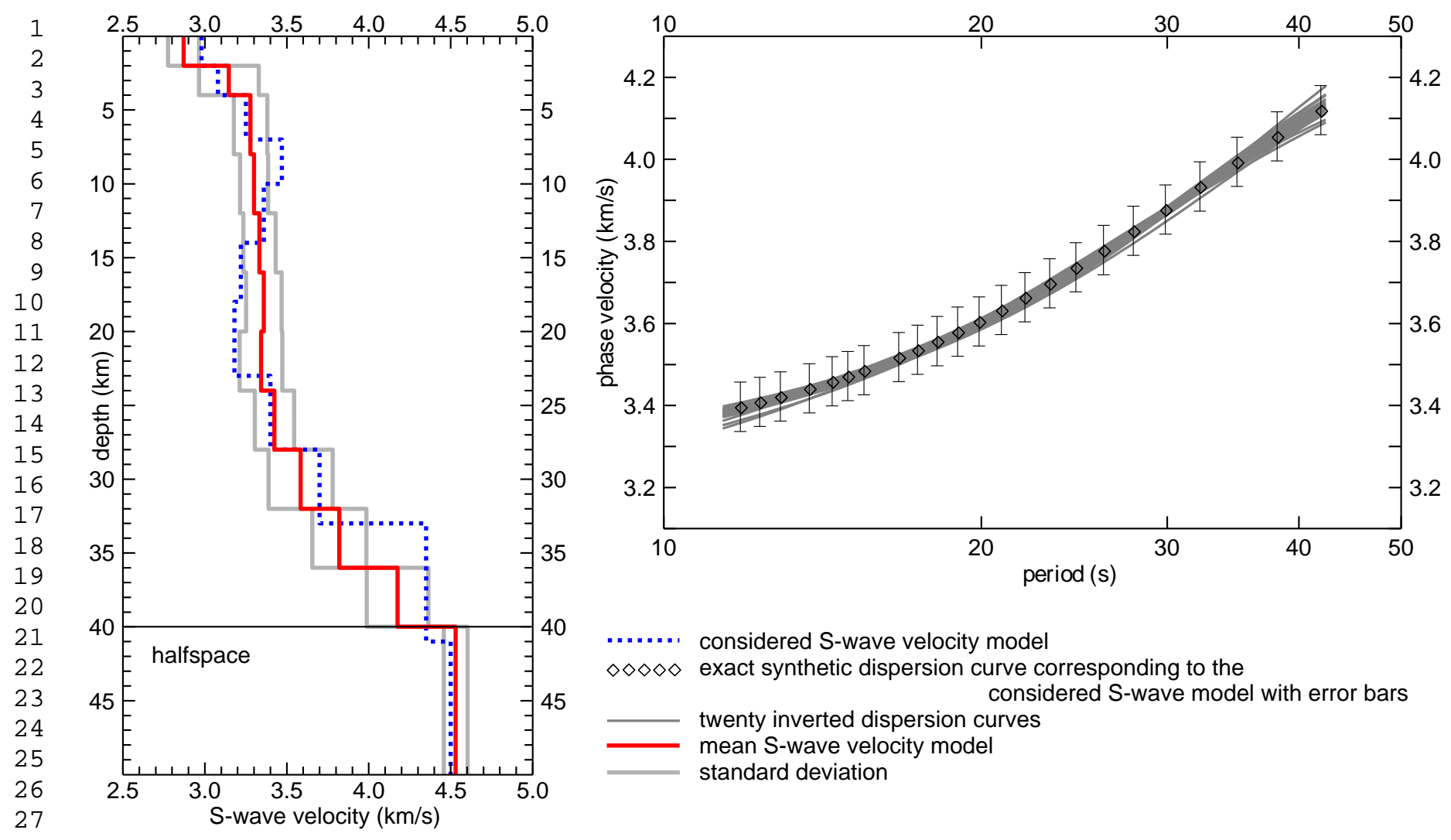

Fig. 6

Dispersion curve inversion test. Dashed blue line in the left panel represents the considered S-wave velocity model. The corresponding exact synthetic dispersion curve is shown in the right panel as diamonds. Error bars are derived from real measurements to make the synthetic test as similar to the real situation as possible. Twenty inverted dispersion curves are drawn as dark gray lines in the right panel and the resultant mean S-wave velocity distribution is plotted as the solid red line in the left panel. Light gray lines represent its standard deviation. 

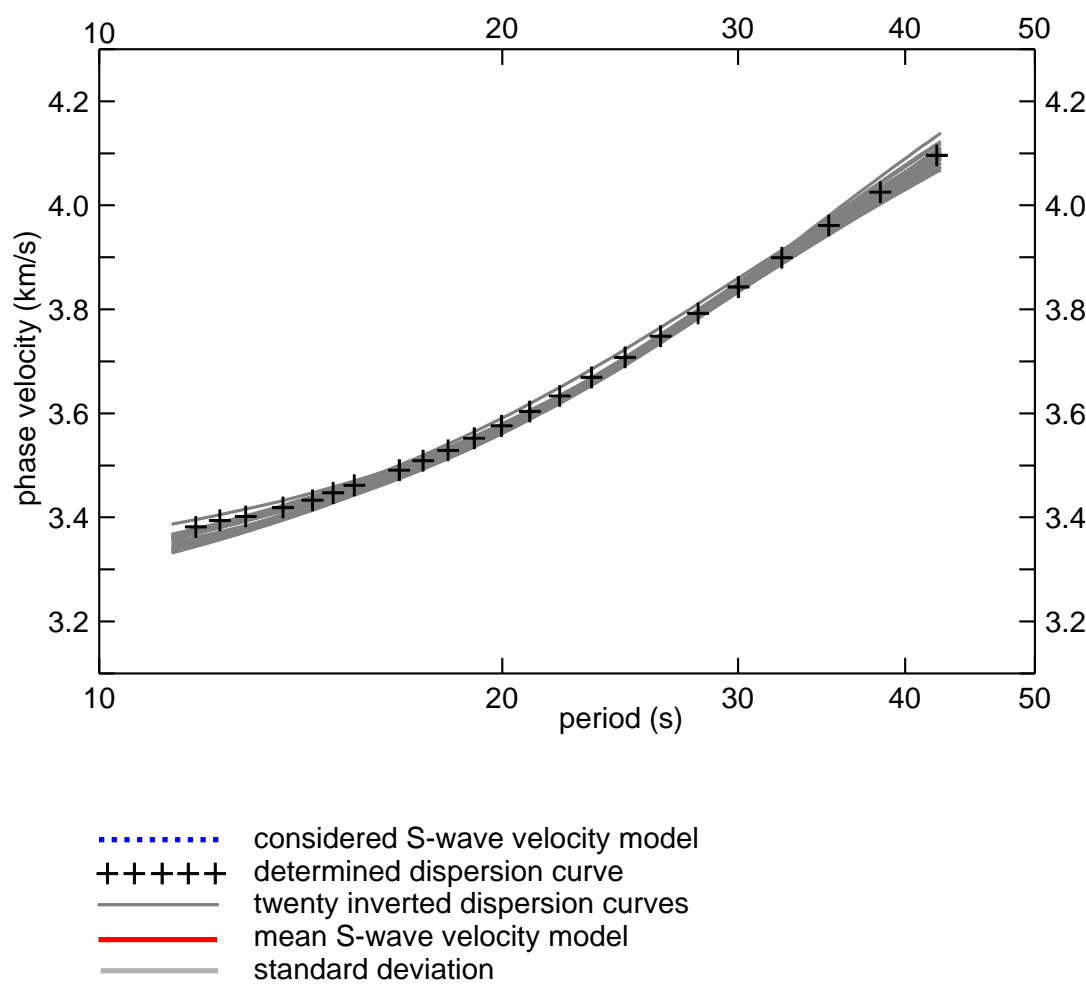

\section{Fig. 7}

Combined test of the analysis and inversion. Dashed blue line in the left plot represents the considered model. Crosses in the right plot represent the dispersion curve determined by the surface wave analysis using synthetic seismograms. Dark gray lines represent twenty dispersion curves found by the inversion. Bold red line in the left plot is the mean shear wave velocity model with its standard deviation given by light gray lines. 


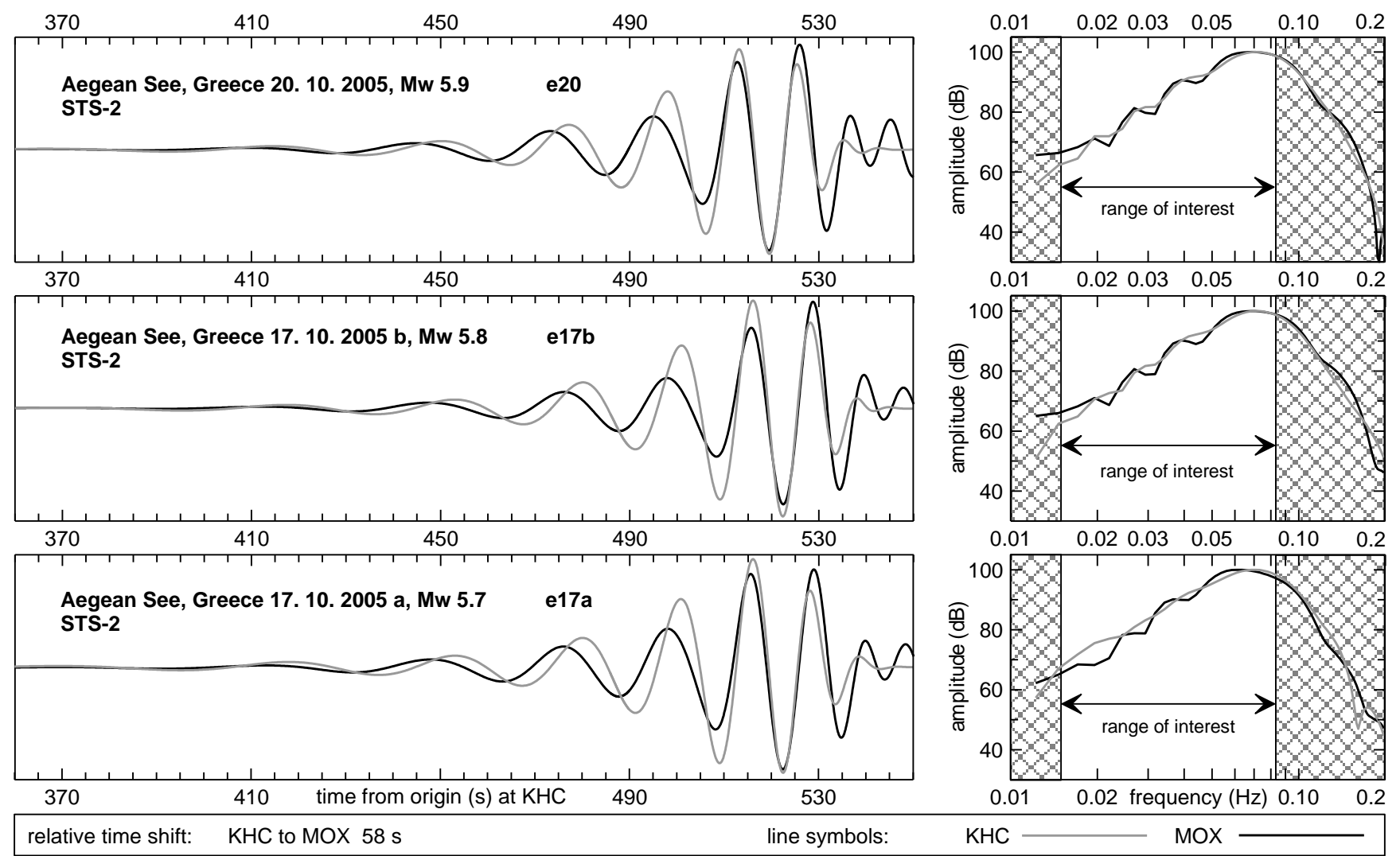

Fig. 8

KHC-MOX profile: Filtered fundamental modes and amplitude spectra of Love waves from three Aegean Sea earthquakes at two STS-2 stations KHC and MOX, mutually shifted by $38 \mathrm{~s}$ in time, what corresponds to the phase velocity around $4.0 \mathrm{~km} / \mathrm{s}$. Instrumental correction is applied both in the time and frequency domain.
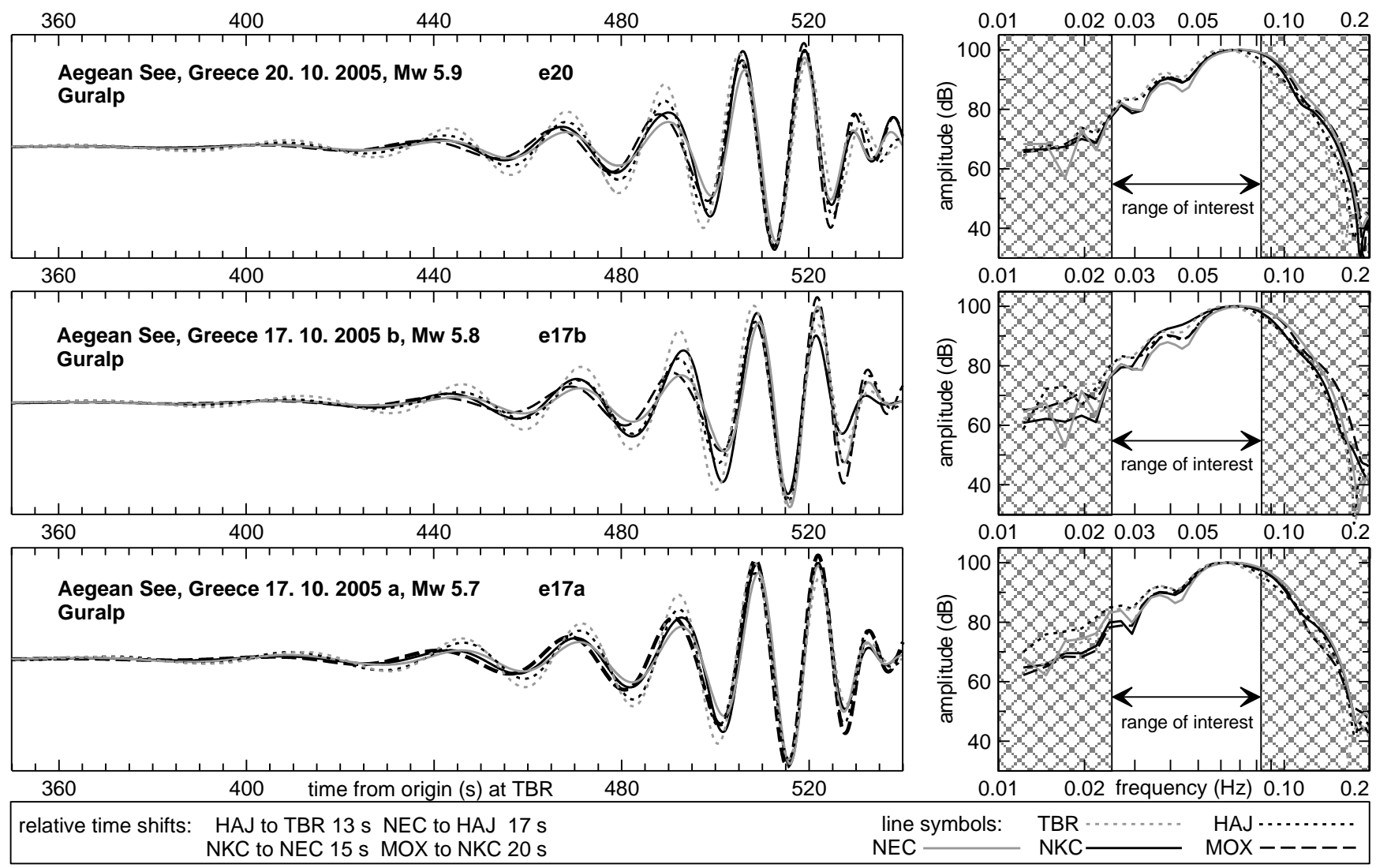

Fig. 9

TBR-MOX profile: Filtered fundamental modes and amplitude spectra of Love waves from three Aegean Sea earthquakes at three Guralp stations TBR, HAJ, NEC and two STS-2 stations NKC and MOX. The mutual time shifts are marked in the figure and correspond to the phase velocity around $4.0 \mathrm{~km} / \mathrm{s}$. Instrumental correction is applied both in the time and frequency domain. 


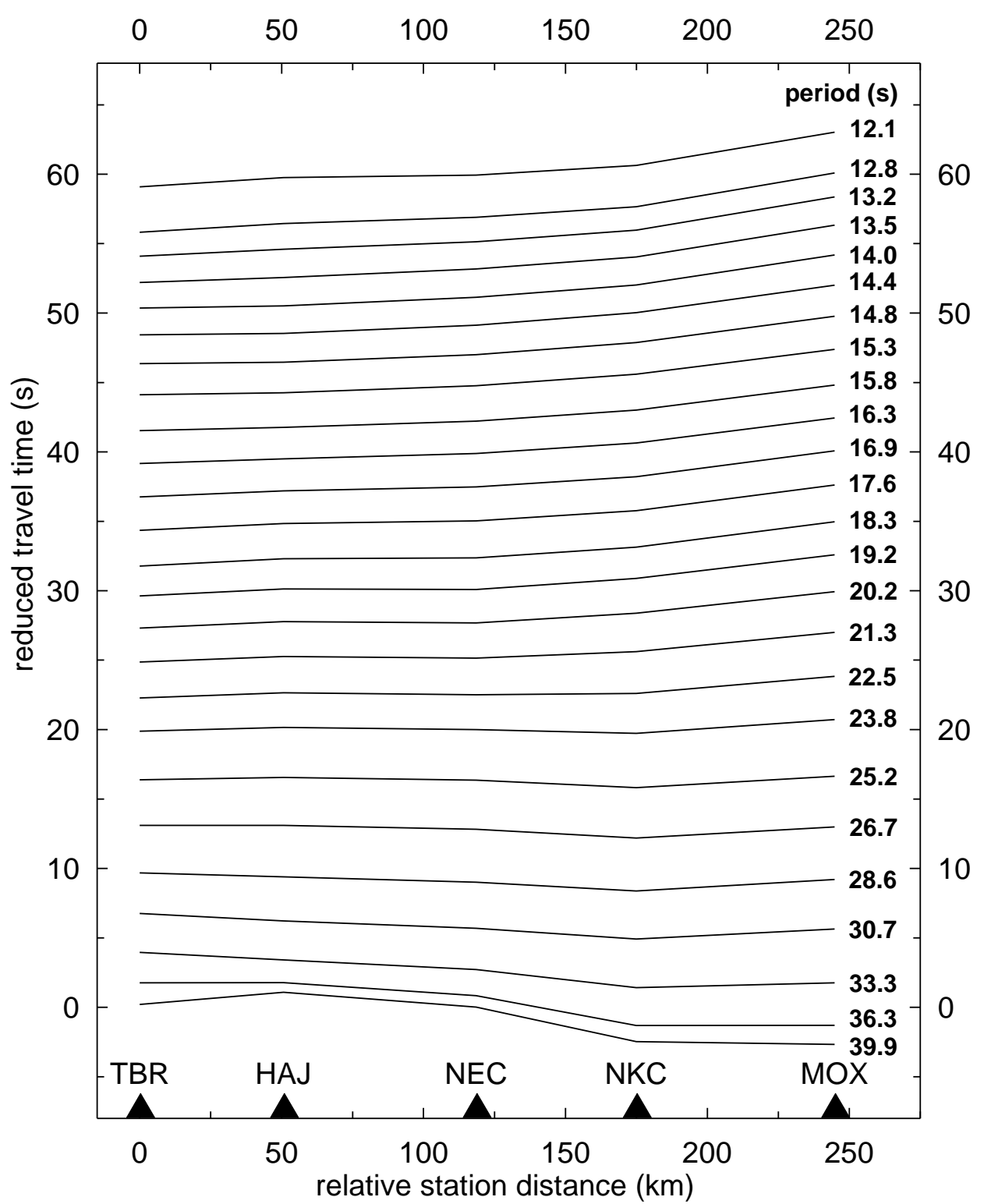

Fig. 10

TBR-MOX profile: Reduced group travel-time curves for periods used along the TBR-MOX profile. The reduction velocity is $4.0 \mathrm{~km} / \mathrm{s}$. 


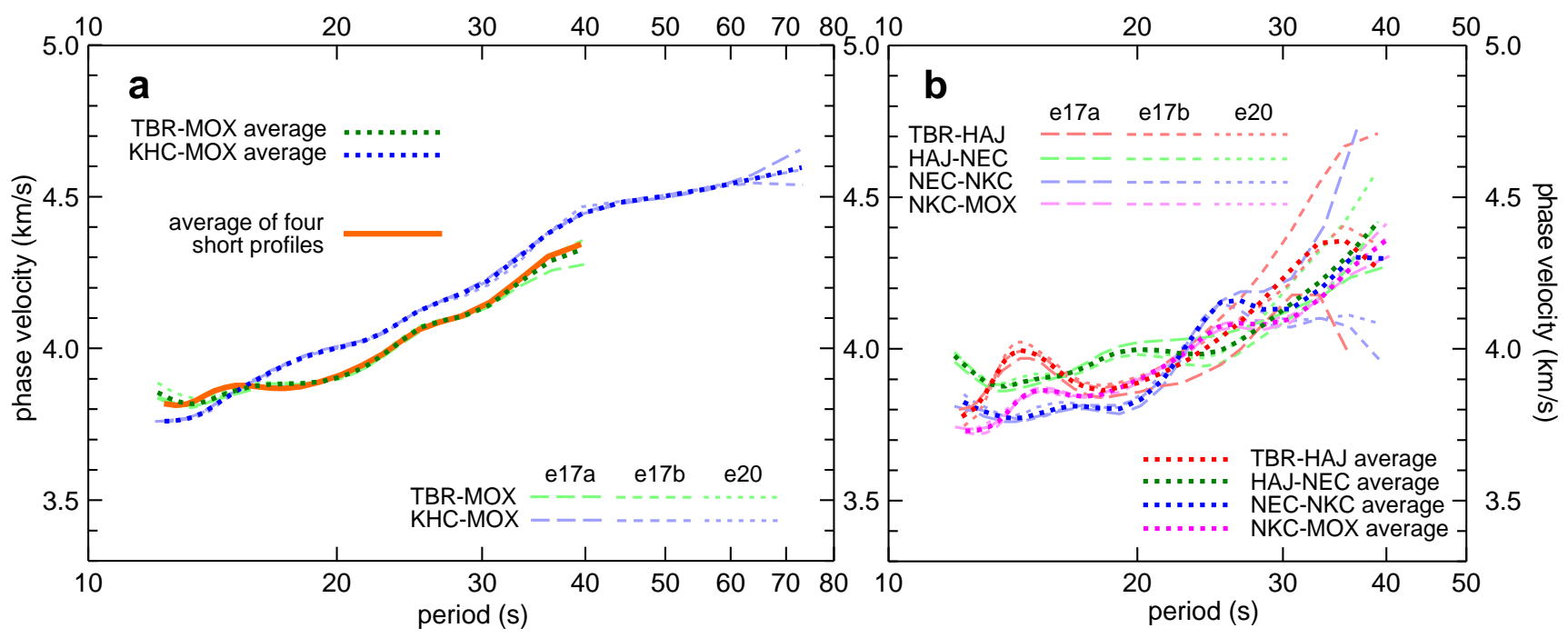

Fig. 11

Measured phase velocity dispersion curves. Panel a: Dispersions for the TBR-MOX and KHC-MOX profiles from three earthquakes are shown as light green and light blue lines, their averages as dark green and dark blue lines, respectively. The dispersion curve taken as the average of four sub-profiles from Panel $\mathbf{b}$ is shown as the solid orange line. Panel b: Dispersions for four sub-profiles dividing the TBR-MOX profile from three earthquakes are shown as light-colored lines and their averages as dark-colored lines.

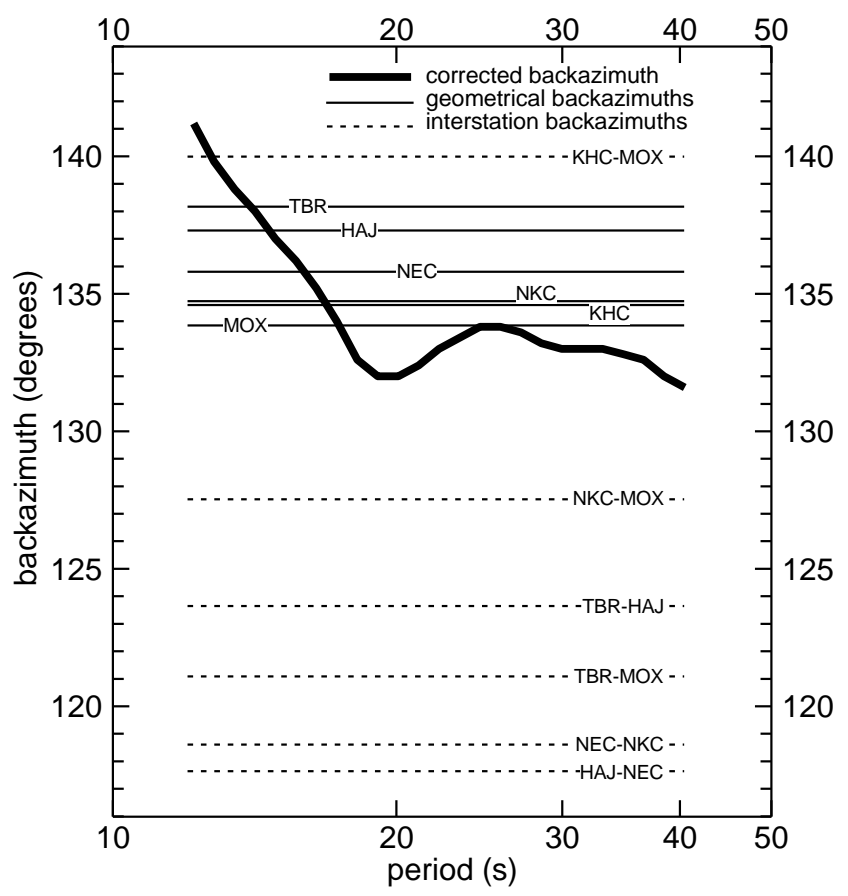

Fig. 12

The bold black line represents the corrected backazimuths of propagation for different periods of Love waves. Thin solid lines show geometrical backazimuths for all six stations (averages for the three events). Dashed lines represent inter-station backazimuths. 


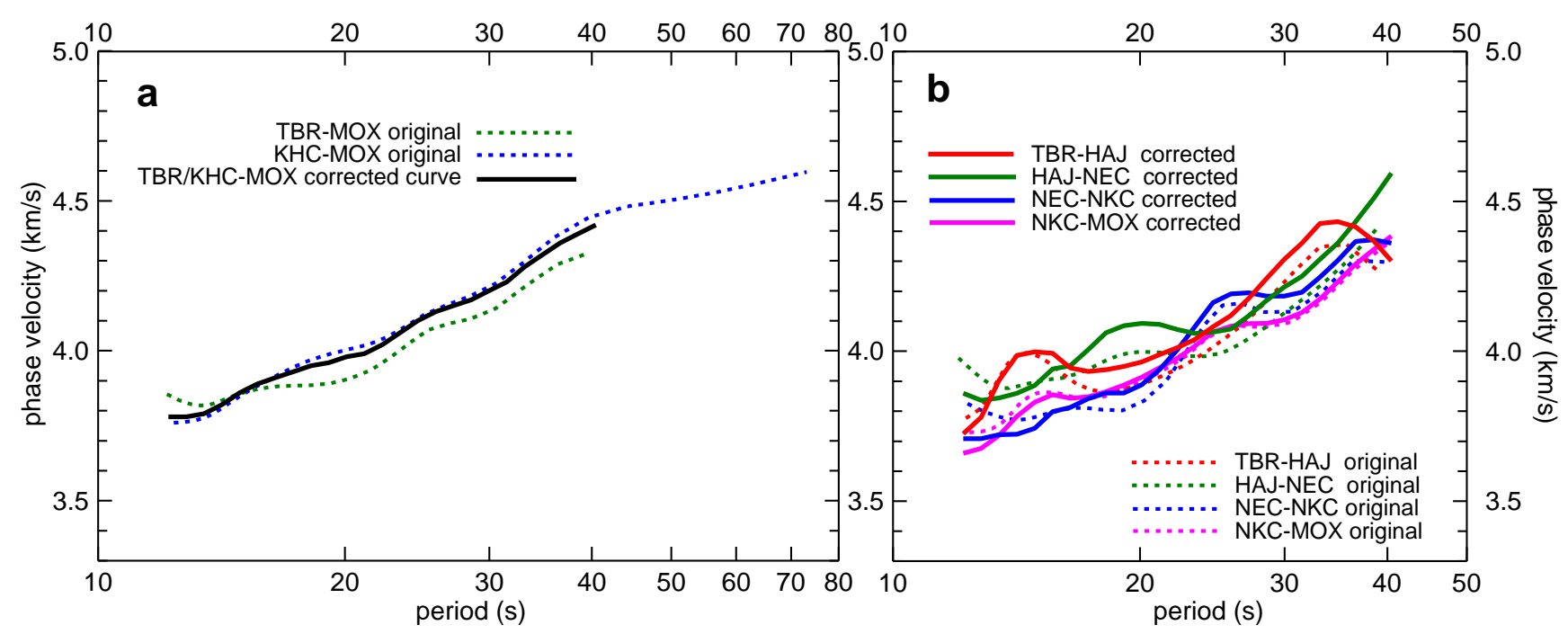

Fig. 13

Corrected dispersion curves (bold) in comparison with measured ones (dashed). Two long profiles (panel a) were used for estimating the corrected curve, which is shown as solid black line. Corrected dispersions are shown (panel b) using the same correction applied to the four sub-profiles. Dashed dark-colored lines are the same as in Fig. 11 in both panels $\mathbf{a}$ and $\mathbf{b}$.

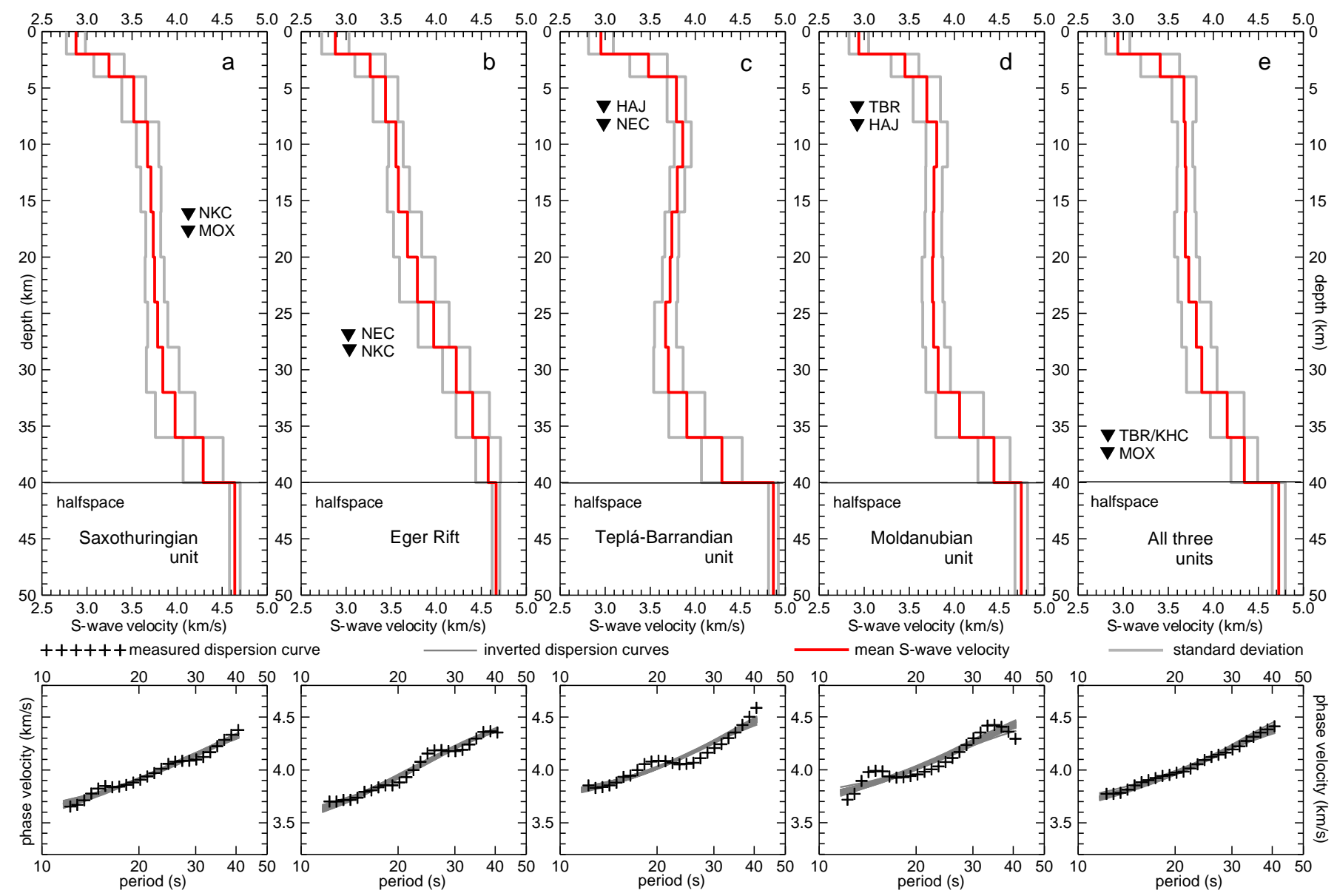

Fig. 14

Determined $\mathrm{v}_{\mathrm{s}}$ structures: (a $\left.-\mathbf{d}\right)$ four short sub-profiles and (e) TBR/KHC-MOX long profile. Standard deviations (gray lines) of mean S-wave velocities (bold red line) from the twenty found models are presented. Crosses in the lower panels represent the backazimuth-corrected dispersion curves entering the inversion. Twenty dispersion curves found by the inversion are shown as dark gray lines. 


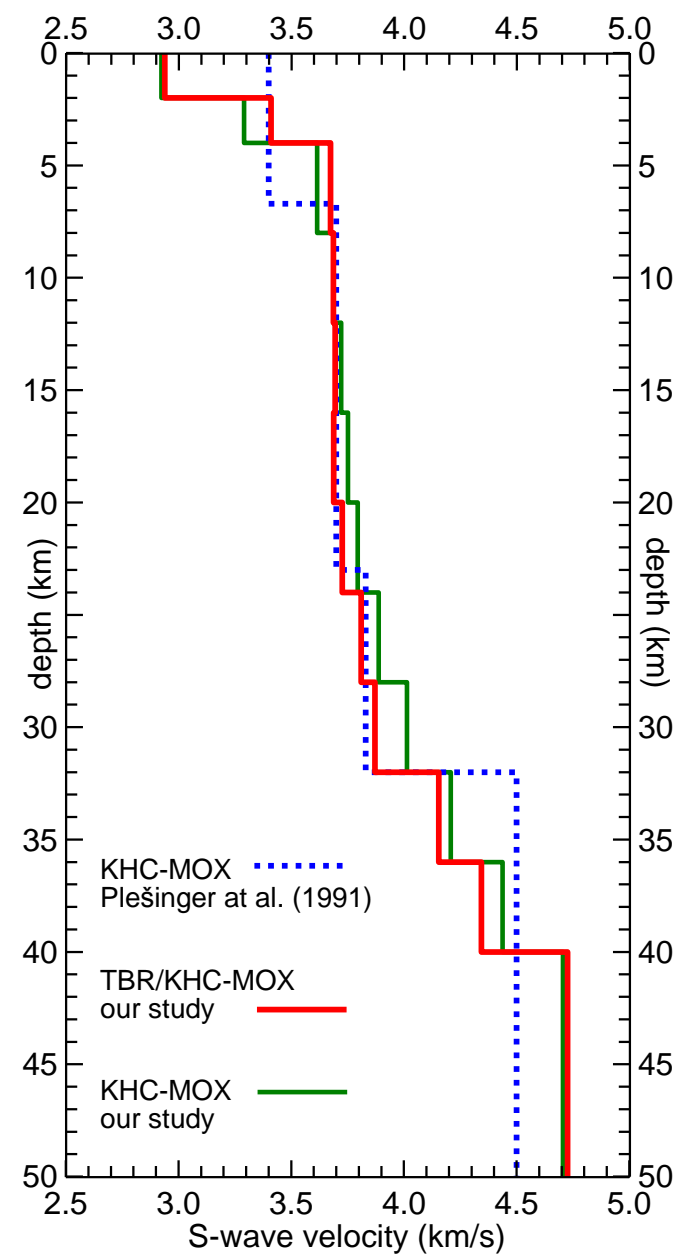

Fig. 15

A comparison of our TBR/KHC-MOX profile (backazimuth-corrected), KHC-MOX profile (uncorrected) with the surface wave profile KHC-MOX measured by Plešinger et al. (1991). 